\title{
Strength anisotropy of fibre-reinforced sands under multiaxial loading
}

\author{
A. MANDOLINI*, A. DIAMBRA $\dagger$ and E. IBRAIM†
}

\begin{abstract}
The strength anisotropy of fibre-reinforced sands in the multiaxial stress space has been investigated using a hollow cylinder torsional apparatus. Probing stress paths under constant cell pressure have been performed on both unreinforced and reinforced sand specimens to assess the influence of the orientation of the principal stress directions on the fibre strengthening contribution. For the first time, a deviatoric strength envelope for fibre-reinforced soils in the multiaxial stress space was identified. The addition of fibres produces an anisotropic increase and a distortion of the deviatoric strength envelope if compared to the unreinforced soil matrix. The fibre strengthening contribution is governed by the tensile strain domain developed and the fibre orientation distribution. Further observations on the effect of the addition of fibres on the volumetric response, principal stress and strain rate non-coaxiality, as well as the shear bands formation of the composite, are presented. An analytical model to capture the anisotropic fibre strengthening contribution is developed and discussed.
\end{abstract}

KEYWORDS: anisotropy; ground improvement; laboratory tests; reinforced soils; sands; stress path

\section{INTRODUCTION}

The strength and deformation characteristics of soils are highly anisotropic. The use of short, discrete, randomly distributed fibres as tension-resisting elements appeared as an attractive engineering option by the prospect of providing soil strength improvement in all loading directions, and thus making the soil behave like a stronger isotropic material. However, evidence from published research suggests that the addition of fibres does not offer any guarantee that the reinforced soil properties will become close to isotropic. In fact, recent laboratory experimental studies on fibre-reinforced sands based on conventional triaxial testing have shown the opposite: although the strength increase is quite significant for compression loading, the fibre effect on ultimate strength is almost negligible for extension loading (Diambra et al., 2010, 2013; Mandolini, 2012). One of the main reasons appears to be the distribution of fibre orientation which, as has already been emphasised by Michałowski \& Čermák (2002), seems to have a central role in controlling the mechanical response of fibrereinforced soils. Diambra et al. (2007), Ibraim et al. (2012) and recently Soriano et al. (2017) demonstrated that, in the laboratory, the fibre orientation induced in specimens by various fabrication techniques may be highly non-uniform, and far from random as is commonly assumed. The fibre and soil mixing, deposition and compaction processes employed in the field (rolling, compaction and/or vibration) are also likely to induce a rather non-uniform fibre orientation distribution, with preferential bedding of fibres, that can result in, or accentuate, the anisotropic mechanical properties of the soil. Similar anisotropic properties are observed for geotextile type reinforced soil, (e.g. Ling \& Tatsuoka, 1994; Kongkitkul et al., 2007; Bostwick et al., 2010). As rotation of the principal axes of stress or strain is expected to occur in

Manuscript received 14 April 2017; revised manuscript accepted 29 March 2018. Published online ahead of print 9 May 2018.

Discussion on this paper closes on 1 August 2019, for further details see $\mathrm{p}$. ii.

Published with permission by the ICE under the CC-BY license. (http://creativecommons.org/licenses/by/4.0/)

* University of Bristol, Bristol, UK (Orcid:0000-0002-9458-0119).

$\dagger$ University of Bristol, Bristol, UK. practice under most types of loading (e.g. Arthur et al., 1980), the characterisation of the strength anisotropy of fibre-reinforced sands presents a need for design and large-scale reinforcement technique implementation that cannot be ignored. Although analytical anisotropic failure criteria of fibre-reinforced soils have been proposed by Michałowski \& Čermák (2002), Michałowski (2008) and Gao \& Zhao (2013), no experimental data supported these modelling developments. Despite the recent proliferation of experimental studies on fibre-reinforced soils, the exploration of the isotropic/anisotropic properties of these materials is still systematically discounted. Therefore, it is the intention, in the present work, to address this limitation through experimental investigation of fibre-reinforced sand strength anisotropy in multiaxial stress conditions using a hollow cylinder torsional apparatus (HCTA). Stress probing paths characterised by different orientations of the principal stress direction are imposed. The failure strength envelope is identified and a new analytical formulation of the failure criteria for fibre-reinforced soil is proposed. Discussion within the context of previously published failure criteria for fibre-reinforced soils (Michałowski, 2008) is also conducted.

\section{HOLLOW CYLINDER TORSIONAL APPARATUS}

The HCTA at the University of Bristol can accommodate hollow cylinder soil specimens with an outer radius $\left(r_{\mathrm{o}}\right)$ of $50 \mathrm{~mm}$, inner radius $\left(r_{\mathrm{i}}\right)$ of $30 \mathrm{~mm}$ and $200 \mathrm{~mm}$ in height $(H)$ (Fig. 1(a)). The apparatus allows independent control of four load components: axial load $(W)$, axial torque $(T)$ applied through the rigid end platens and two confining pressures applied on the specimen's inner and outer flexible lateral surfaces, $p_{\mathrm{i}}$ and $p_{\mathrm{o}}$, respectively (Fig. 1(a)). The degree of stress and strain non-uniformities, which are inevitable in a hollow cylinder specimen as a result of the sample curvature and the restraint at its ends, is directly related to the specimen dimensions. Sayao \& Vaid (1991) suggested the following desirable dimensions of the specimen: $(a)$ wall thickness, $t_{\mathrm{w}}$, between 20 and $26 \mathrm{~mm}$; (b) ratio of inner to outer radius ranging between 0.65 and $0 \cdot 82 ;(c)$ ratio of height to outer diameter from $1 \cdot 8$ to $2 \cdot 2$. The specimen dimensions used in this study satisfy the first and third conditions, while for the second one, the ratio is close to the lower limit. Compared 


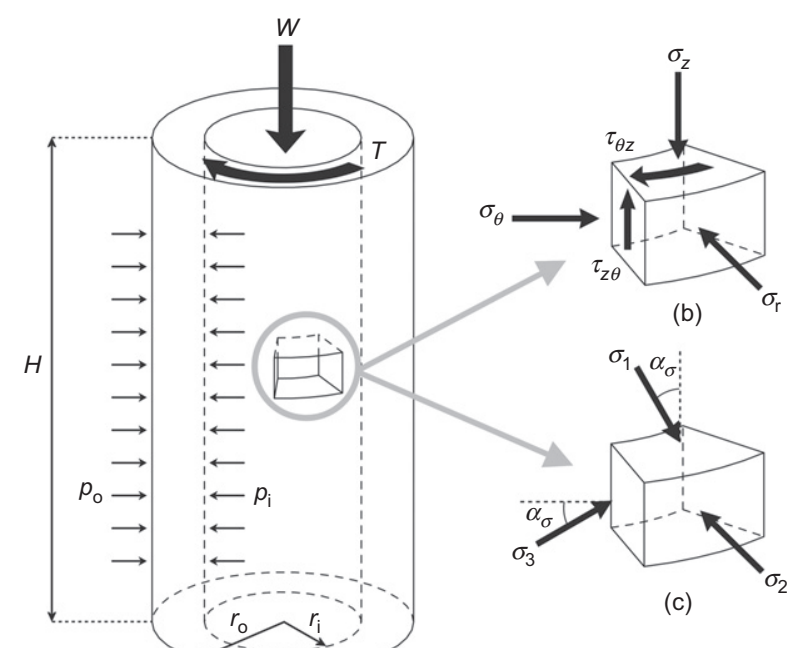

(a)

Fig. 1. Definition of forces and stress state in hollow cylinder specimen: (a) loading conditions on the hollow cylinder specimen; (b) stress components; (c) main principal stresses on a representative element of the specimen's wall

with an average value, the shear strain across the wall varies between $\pm t_{\mathrm{w}} / D$, where $D$ is the average diameter. A low ratio of wall thickness to diameter would increase the uniformity of the shear strain, but would also increase the gradient of radial stress if internal and external pressures are not the same. A compromise is necessary.

The HCTA is fitted with a submersible combined force/torque load cell with $8 \mathrm{kN} / 400 \mathrm{Nm}$ capacity placed inside the confining cell. The overall axial displacement $(\Delta H)$ and twist $(\Delta \theta)$ measurements are provided by linear variable differential transformers (LVDTs) and a rotary capacitive displacement transducer (RCDT), respectively. Both transducers are located outside the pressurised cell. Two identical volume change devices are also used, one for the measurement of the overall sample volume, and the other one for the inner cell variations. Three pressure transducers for continuous recording of the inner cell, $p_{\mathrm{i}}$, outer cell, $p_{\mathrm{o}}$, and pore water, $u$, pressures also equip the HCTA. Details about the apparatus are given in Yoon (2005), Ibraim et al. (2011) and Mandolini (2014). The relationships for the calculation of the average stresses (axial $\left(\sigma_{z}\right)$, radial $\left(\sigma_{\mathrm{r}}\right)$, circumferential $\left(\sigma_{\theta}\right)$ and shear $\left(\tau_{\theta z}\right)$ ) and strains (axial $\left(\varepsilon_{z}\right)$, radial $\left(\varepsilon_{\mathrm{r}}\right)$, circumferential $\left(\varepsilon_{\theta}\right)$ and shear $\left.\left(\gamma_{\theta z}\right)\right)$ follow Hight et al. (1983), Miura et al. (1986) and Vaid et al. (1990); they are listed in Table 1. Corrections due to the membrane's resistances to the applied axial, radial and shear stress have been accounted for using the method suggested by Tatsuoka et al. (1986). However, as the volume changes due to membrane penetration were found to be negligible, no correction has been applied.

The state of stress of a representative soil element can be represented by the mean stress, $p$, generalised deviatoric component of stress, $q$, the angle between the major principal stress direction and vertical $z$-axis, $\alpha_{\sigma}$, and the intermediate principal stress ratio, $b$, parameters defined as

$$
\begin{aligned}
& p=\frac{\sigma_{z}+\sigma_{\theta}+\sigma_{\mathrm{r}}}{3}=\frac{\sigma_{1}+\sigma_{2}+\sigma_{3}}{3} \\
& q=\sqrt{\frac{\left(\sigma_{z}-\sigma_{\mathrm{r}}\right)^{2}+\left(\sigma_{\mathrm{r}}-\sigma_{\theta}\right)^{2}+\left(\sigma_{\theta}-\sigma_{z}\right)^{2}}{2}+3 \tau_{\theta z}^{2}} \\
& \alpha_{\sigma}=\frac{1}{2} \tan ^{-1}\left(\frac{2 \tau_{\theta z}}{\sigma_{z}-\sigma_{\theta}}\right) \\
& b=\frac{\sigma_{2}-\sigma_{3}}{\sigma_{1}-\sigma_{3}}
\end{aligned}
$$

where $\sigma_{1}, \sigma_{2}$ and $\sigma_{3}$ are the major, intermediate and minor principal stresses, respectively (Fig. 1(c)).

In the $\left(\left(\sigma_{z}-\sigma_{\theta}\right) / 2, \tau_{\theta z}\right)$ stress plane, which is commonly employed to plot stress conditions applied in experimental tests using the HCTA, a vector from the origin to the current stress state has a length equal to the radius of Mohr's circle of stress, and makes an angle equal to $2 \alpha_{\sigma}$ from the axis $\left(\sigma_{z}-\sigma_{\theta}\right) / 2$. The magnitude of the vector is the maximum shear stress, $\tau_{\max }$, applied to the sample

$$
\begin{aligned}
\tau_{\max } & =\sqrt{\frac{\left(\sigma_{z}-\sigma_{\theta}\right)^{2}}{2}+\tau_{\theta z}^{2}} \\
& =\frac{\sigma_{1}-\sigma_{3}}{2}
\end{aligned}
$$

The stress components $\left(p, q, \tau_{\theta z}\right)$ are work-conjugate with the strain components $\left(\varepsilon_{\mathrm{v}}, \varepsilon_{q}, \gamma_{\theta z}\right)$, volumetric strain, $\varepsilon_{\mathrm{v}}$, deviatoric strain, $\varepsilon_{q}$, and shear strain, $\gamma_{\theta z}$, with

$$
\begin{aligned}
& \varepsilon_{\mathrm{V}}=\varepsilon_{z}+\varepsilon_{\mathrm{r}}+\varepsilon_{\theta} \\
& \varepsilon_{q}=\frac{\sqrt{2\left(\varepsilon_{z}-\varepsilon_{\mathrm{r}}\right)^{2}+2\left(\varepsilon_{\mathrm{r}}-\varepsilon_{\theta}\right)^{2}+2\left(\varepsilon_{\theta}-\varepsilon_{z}\right)^{2}+3 \gamma_{\theta \mathrm{r}}^{2}}}{3}
\end{aligned}
$$

In the $\left(\delta \varepsilon_{z}-\delta \varepsilon_{\theta}, \delta \gamma_{z \theta}\right)$ strain increment plane, the major principal strain increment occurs at an angle $\alpha_{\delta \varepsilon}$ to the vertical $z$-axis

$$
\alpha_{\delta \varepsilon}=\frac{1}{2} \tan ^{-1}\left(\frac{\delta \gamma_{\theta z}}{\delta \varepsilon_{z}-\delta \varepsilon_{\theta}}\right)
$$

Table 1. Equations of average stress and strain components (Hight et al., 1983; Miura et al., 1986; Vaid et al., 1990)

\begin{tabular}{l|l|l}
\hline Axis direction & Stress equations & Strain equations \\
\hline Axial normal & $\sigma_{z}=\frac{p_{\mathrm{i}} r_{\mathrm{i}}^{2}-p_{\mathrm{o}} r_{\mathrm{o}}^{2}}{r_{\mathrm{o}}^{2}-r_{\mathrm{i}}^{2}}+\frac{W}{\pi\left(r_{\mathrm{o}}^{2}-r_{\mathrm{i}}^{2}\right)}$ & $\varepsilon_{z}=-\frac{\Delta H}{H}$ \\
Radial normal & $\sigma_{\mathrm{r}}=\frac{p_{\mathrm{i}} r_{\mathrm{i}}^{2}-p_{\mathrm{o}} r_{\mathrm{o}}^{2}}{r_{\mathrm{o}}^{2}-r_{\mathrm{i}}^{2}}-\frac{2\left(p_{\mathrm{o}}-p_{\mathrm{i}}\right) r_{\mathrm{o}}^{2} r_{\mathrm{i}}^{2} \ln \left(r_{\mathrm{o}} / r_{\mathrm{i}}\right)}{\left(r_{\mathrm{o}}^{2}-r_{\mathrm{i}}^{2}\right)^{2}}$ & $\varepsilon_{\mathrm{r}}=-\frac{\Delta r_{\mathrm{o}}-\Delta r_{\mathrm{i}}}{r_{\mathrm{o}}-r_{\mathrm{i}}}$ \\
Circumferential normal & $\sigma_{\theta}=\frac{p_{\mathrm{i}} r_{\mathrm{i}}^{2}-p_{\mathrm{o}} r_{\mathrm{o}}^{2}}{r_{\mathrm{o}}^{2}-r_{\mathrm{i}}^{2}}+\frac{2\left(p_{\mathrm{o}}-p_{\mathrm{i}}\right) r_{\mathrm{o}}^{2} r_{\mathrm{i}}^{2} \ln \left(r_{\mathrm{o}} / r_{\mathrm{i}}\right)}{\left(r_{\mathrm{o}}^{2}-r_{\mathrm{i}}^{2}\right)^{2}}$ & $\varepsilon_{\theta}=-\frac{\Delta r_{\mathrm{o}}+\Delta r_{\mathrm{i}}}{r_{\mathrm{o}}+r_{\mathrm{i}}}$ \\
Circumferential shear & $\tau_{\theta z}=\tau_{z \theta}=\frac{3 T}{2 \pi\left(r_{\mathrm{o}}^{3}-r_{\mathrm{i}}^{3}\right)}$ & $\gamma_{\theta z}=\frac{2 \theta \pi\left(r_{\mathrm{o}}^{3}-r_{\mathrm{i}}^{3}\right)}{3 H\left(r_{\mathrm{o}}^{2}-r_{\mathrm{i}}^{2}\right)}$ \\
\hline
\end{tabular}




\section{MATERIALS AND SAMPLE FABRICATION}

Materials

Hostun RF (S28) sand is a standard European material for laboratory testing with a high siliceous content $\left(\mathrm{SiO}_{2}>98 \%\right)$, and angular to sub-angular grains. Its grain size distribution is shown in Fig. 2(a) and its physical properties are summarised in Table 2.

Loksand crimped cylindrical polypropylene fibres have been used as reinforcing material. These fibres have a diameter of $0.1 \mathrm{~mm}$ and they have been cut to length, $l_{\mathrm{f}}=17.5 \mathrm{~mm}$, which generally corresponds to about $15 \mathrm{~mm}$ linear length $\left(L_{\mathrm{f}}\right)$ if their crimps are neglected, as shown in Fig. 2(b). The ratio of fibre linear length/HCTA specimen

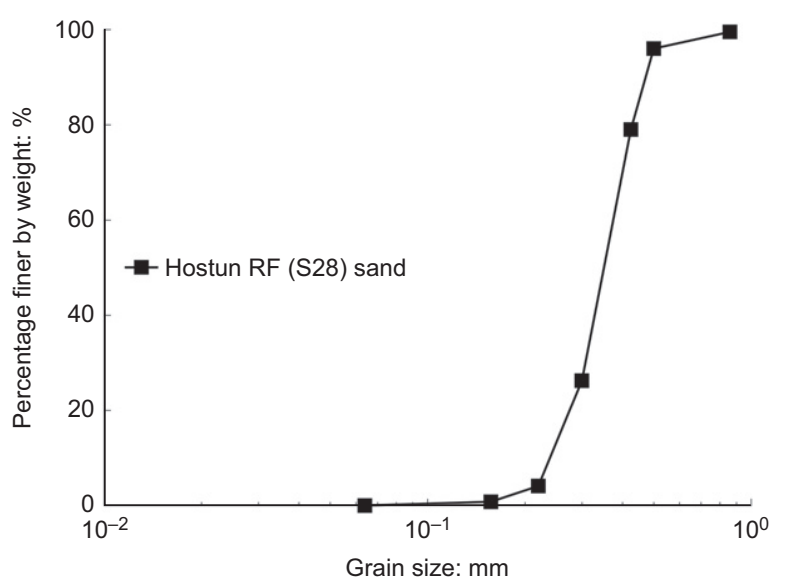

(a)

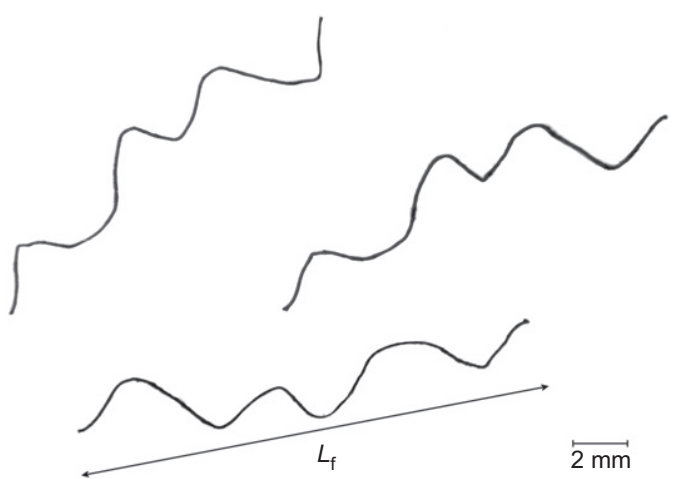

(b)

Fig. 2. (a) Grain size distribution for Hostun RF (S28) sand. (b) Microscopic two-dimensional view of individual crimped polypropylene fibres wall thickness is about $0 \cdot 75$, slightly higher than the recommendations of Ang \& Loehr (2003), who suggest a limiting value of 0.70 (in order to consider a sample reasonably representative of the mass property of fibrereinforced soil). However, a compromise was necessary to ensure a measurable fibre strengthening contribution (Diambra \& Ibraim, 2015). Other fibre properties are provided in Table 2.

\section{Specimen fabrication procedure}

Owing to the sample's thin wall, curvature and height, laboratory fabrication of hollow cylindrical sand samples is relatively challenging. When fibres are used as reinforcement, the sample fabrication requires further attention due to the desire to preserve uniformity of fibre distribution, and avoid segregation of its constituents. Typically, the fibre-reinforced sand specimen fabrication procedure involves two stages: mixing and formation. The process begins with the manual mixing of the sand with a controlled amount of water (10\% moisture content). While continuing the mixing, small amounts of fibres are then added progressively, until, by visual examination, the fibres appear to be well distributed throughout the soil mass. The water is required to enable a good blending between the sand and fibres, and also to prevent their segregation. The concentration of fibres $\left(w_{\mathrm{f}}\right)$ used in the reinforced specimens is defined as the ratio of the weight of fibres $\left(W_{\mathrm{f}}\right)$ to the dry weight of sand $\left(W_{\mathrm{s}}\right)$

$$
w_{\mathrm{f}}=W_{\mathrm{f}} / W_{\mathrm{s}}
$$

The mixing process is followed by the sample formation. In general, for direct shear and triaxial testing specimens, a number of compacted layers of equal thickness (not higher than $25 \mathrm{~mm}$ ) are employed in a so-called moist tamping procedure (Ibraim \& Fourmont, 2006; Diambra et al., 2010). Therefore, the moist tamping procedure using eight equally compacted layers was initially considered for the hollow cylindrical samples. However, several trials systematically showed poor quality of the hollow cylindrical samples with visible non-uniformities throughout the whole sample height. Based on previous work by Ibraim et al. (2012), an alternative procedure employing a moist vibration technique was subsequently considered. The mechanical responses of reinforced cylindrical samples in triaxial testing, prepared with the two fabrication methods - moist tamping and moist vibration - proved to be qualitatively similar (Ibraim et al., 2012). Therefore, the whole moist fibre-soil mixture was gently transferred inside the specimen's mould, through the use of a specially designed funnel, to avoid structural disturbance. After depositing the mixture,

Table 2. Characteristics of the sand and fibres used in the experimental investigation

\begin{tabular}{l|l|c|c|c|c|c}
\hline \multicolumn{7}{l}{ Hostun RF sand } \\
$\begin{array}{l}\text { Siliceous } \\
\text { amount: } \%\end{array}$ & Grain shape & $\begin{array}{c}\text { Mean grain } \\
\text { size, } \\
D_{50}: \mathrm{mm}\end{array}$ & $\begin{array}{c}\text { Coefficient } \\
\text { of } \\
\text { uniformity, } \\
C_{\mathrm{u}}=D_{60} / D_{10}\end{array}$ & $\begin{array}{c}\text { Coefficient of } \\
\text { gradation, } \\
C_{\mathrm{g}}=\left(D_{30}\right)^{2} /\left(D_{60} D_{10}\right)\end{array}$ & $\begin{array}{c}\text { Specific } \\
\text { gravity, } G_{\mathrm{s}}\end{array}$ & $\begin{array}{c}\text { Max. and min. } \\
\text { voids ratio, } \\
e_{\max } \div e_{\min }\end{array}$ \\
\hline Silica, $\mathrm{SiO}_{2}>98$ & Angular to sub-angular & $0 \cdot 32$ & $1 \cdot 70$ & $1 \cdot 1$ & $2 \cdot 65$ & $1 \cdot 000 \div 0 \cdot 630$ \\
\hline
\end{tabular}

Fibres

\begin{tabular}{l|l|c|c|c|c|c|c}
\hline $\begin{array}{l}\text { Specific } \\
\text { gravity, } G_{\mathrm{f}}\end{array}$ & Cross-section & $\begin{array}{c}\text { Length, } l_{\mathrm{f}}: \\
\mathrm{mm}\end{array}$ & $\begin{array}{c}\text { Diameter, } d_{\mathrm{f}}: \\
\mathrm{mm}\end{array}$ & $\begin{array}{c}\text { Aspect ratio, } \\
\eta_{\mathrm{f}}=l_{\mathrm{f}} / d_{\mathrm{f}}\end{array}$ & $\begin{array}{c}\text { Tensile } \\
\text { strength: MPa }\end{array}$ & $\begin{array}{c}\text { Elastic } \\
\text { modulus: MPa }\end{array}$ & $\begin{array}{c}\text { Elongation at } \\
\text { break: } \%\end{array}$ \\
\hline 0.91 & Circular & $17 \cdot 5$ & $0 \cdot 1$ & 175 & 22.5 & 900 & 160 \\
\hline
\end{tabular}


the sample mould was subjected to a vertically dominated vibration imposed by a shaker under a frequency of about $50 \mathrm{~Hz}$ and acceleration of $2 \mathrm{~g}$, and with a constant very light soil surcharge of $2.8 \mathrm{kPa}$ provided by a vertically guided hollow circular top cap. The fibre-sand mixture underwent vibration until the target sample density was achieved. It was decided to transfer the soil into the mould in five equal successive layers, in order to minimise segregation of the fibres, and then vibrate the whole mixture. This procedure led to a good repeatability of the deviatoric stress-strain response for experimental tests carried out in the HCTA following the stress path for a conventional drained triaxial compression test (Fig. 3(a)). The small but noticeable variability of the volumetric response (Fig. 3(b)) can be ascribed to the small variations in void ratio among the tested samples, which are known to affect the volumetric performances more than the shear stress-strain responses, as was thoroughly investigated by Diambra (2010). Sample fabrication details, experimental conditions and the test results for these trial samples are given in Table 3.

\section{EXPERIMENTAL RESULTS IN THE MULTIAXIAL STRESS SPACE \\ Programme of testing}

The experimental programme consisted of a total of 24 drained tests imposing six different probing stress paths with different values of the orientation of the major principal stress direction, $\alpha_{\sigma}$, on both unreinforced and reinforced

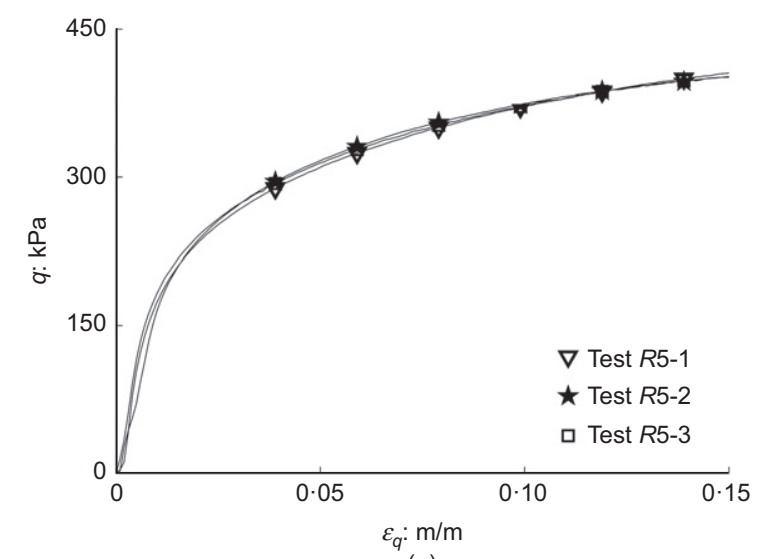

(a)

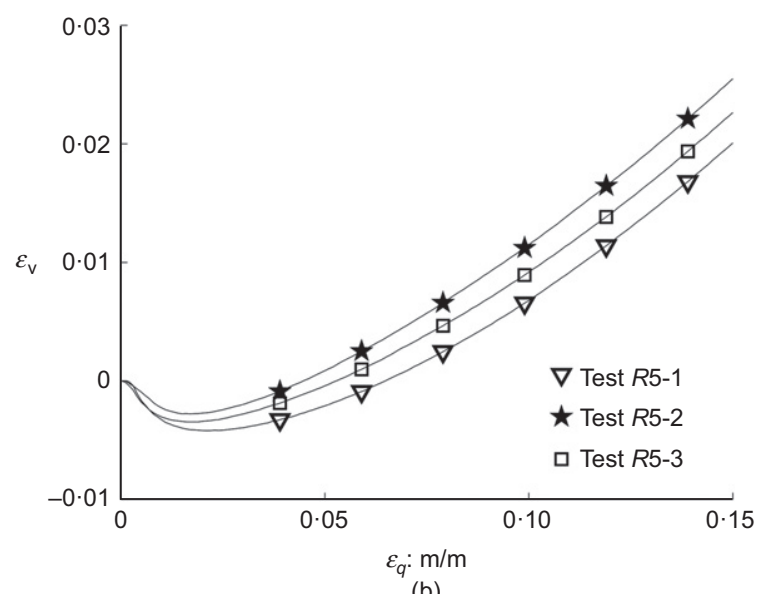

(b)

Fig. 3. (a) Deviatoric stress-strain; (b) volumetric trends for the specimens reinforced with $w_{\mathrm{f}}=\mathbf{0 . 5} \%$ of fibres tested in HCTA following the stress path for triaxial compression under an effective cell confining pressure of $100 \mathrm{kPa}$
Table 3. Properties of reinforced specimens made for the repeatability assessment

\begin{tabular}{l|c|c|c}
\hline Test name & R5-1 & R5-2 & R5-3 \\
\hline$\sigma_{\mathrm{c}}^{\prime}: \mathrm{kPa}$ & 100 & 100 & 100 \\
$w_{\mathrm{f}}: \%$ & $0 \cdot 5$ & $0 \cdot 5$ & $0 \cdot 5$ \\
$e$ & $0 \cdot 950$ & $0 \cdot 950$ & $0 \cdot 960$ \\
$e_{\mathrm{c}}$ & $0 \cdot 943$ & $0 \cdot 943$ & $0 \cdot 948$ \\
$\phi_{10}^{\prime}: \mathrm{deg}$ & $40 \cdot 6$ & $40 \cdot 6$ & $40 \cdot 6$ \\
$q_{10}: \mathrm{kPa}$ & $374 \cdot 5$ & $372 \cdot 1$ & $371 \cdot 5$ \\
\hline
\end{tabular}

Note: $e$ is the fabrication void ratio; $e_{\mathrm{c}}$ is the void ratio after consolidation; $\phi_{10}^{\prime}$ and $q_{10}$ represent the mobilised friction angle and the deviatoric stress at $\varepsilon_{q}=10 \%$, respectively; $\sigma_{\mathrm{c}}^{\prime}$ indicates the effective confining cell pressure employed.

$\left(w_{\mathrm{f}}=0 \cdot 5 \%\right)$ specimens, isotropically consolidated to two different cell confining pressures $\left(p_{\mathrm{i}}^{\prime}=p_{\mathrm{o}}^{\prime}=100\right.$ and $200 \mathrm{kPa}$ ). The probing stress path under constant $\alpha_{\sigma}$ requires the simultaneous application of small axial and torsional stress increments on the specimen. As unreinforced material exhibited a slight softening behaviour, the shearing was initially conducted in a stress-controlled mode until the deviatoric strain $\left(\varepsilon_{q}\right)$ reached a value about $0 \cdot 2 \%$. The control was then switched to the strain-controlled mode, for the latter part of the testing, keeping a strain rate of about $0.3 \% / \mathrm{min}$.

The samples were tested in fully saturated conditions, which were ensured by carbon dioxide $\left(\mathrm{CO}_{2}\right)$ flushing method together with employment of water back-pressure up to $300 \mathrm{kPa}$. Values of the Skempton coefficient of at least 0.95 were systematically obtained. The target fabrication void ratio chosen for all the unreinforced specimens was around 0.95 , while for the reinforced specimen the same quantity of sand, $W_{\mathrm{s}}$, was used when fibres were added, which for a constant specimen total volume resulted in a very slight reduction of the fabrication void ratio of fibre-reinforced samples. A list of the tests performed including test name, loading mode, fibre content $\left(w_{\mathrm{f}}\right)$, void ratio after consolidation $\left(e_{\mathrm{c}}\right)$, direction of major principal stress $\left(\alpha_{\sigma}\right)$, intermediate principal stress parameter $(b)$ and cell confining pressure $\left(\sigma_{\mathrm{c}}^{\prime}\right)$ is provided in Table 4 . The table also includes the main experimental results in terms of deviatoric strength $\left(q_{10}\right)$, stress ratio $\left(\eta_{10}=q_{10} / p_{10}^{\prime}\right)$ and friction angle $\left(\phi_{10}^{\prime}\right)$ at a deviatoric strain $\varepsilon_{q}=10 \%$. The limit of $10 \%$ deviatoric strain has been defined as a serviceability failure criterion. The friction angle $\phi_{10}^{\prime}$ has been determined based on the Matsuoka-Nakai failure criterion (Matsuoka \& Nakai, 1974 ) in the multiaxial stress space. The test names provide information about the cell confinement pressure employed (H100 or H200) and the fibre content (f00 or f05), with the last number referring to the imposed direction angle of the major principal stress $\left(\alpha_{\sigma}\right)$.

\section{Experimental results}

The actual imposed stress paths of all the tests are presented in Fig. 4 and, with only one exception (test H200f05_60, Fig. 4) due to an error on the stress control procedure, follow the prescribed stress paths well.

Deviatoric stress-strain response. The deviatoric stressstrain $\left(q-\varepsilon_{q}\right)$ responses for the tests performed are shown in Fig. 5, where the comparison between unreinforced and reinforced sand specimens for similar value of $\alpha_{\sigma}$, and for both confining pressures, are reported in each sub-figure. The deviatoric strength of both reinforced and unreinforced specimens decreases with increasing value of $\alpha_{\sigma}$, a 
Table 4. List of the tests performed investigating the strength anisotropy of fibre-reinforced sands under generalised loading conditions using the HCTA; $q_{10}, \eta_{10}$ and $\phi_{10}^{\prime}$ are, respectively, the deviatoric stress, stress ratio and friction angle at $\varepsilon_{q}=10 \%$

\begin{tabular}{|c|c|c|c|c|c|c|c|c|c|}
\hline Test name & Loading type & $\alpha_{\sigma}: \operatorname{deg}$ & $b$ & $\sigma_{\mathrm{c}}^{\prime}: \mathrm{kPa}$ & $w_{\mathrm{f}}: \%$ & $e_{\mathrm{c}}$ & $q_{10}: \mathrm{kPa}$ & $\eta_{10}$ & $\phi_{10}^{\prime}: \operatorname{deg}$ \\
\hline H100f00_0 & Compression & 0 & 0 & 100 & 0 & 0.949 & $219 \cdot 0$ & $1 \cdot 27$ & $31 \cdot 6$ \\
\hline H100f05_0 & Compression & 0 & 0 & 100 & $0 \cdot 5$ & 0.943 & $364 \cdot 7$ & $1 \cdot 63$ & $39 \cdot 9$ \\
\hline H200f00_0 & Compression & 0 & 0 & 200 & 0 & 0.934 & $462 \cdot 7$ & $1 \cdot 30$ & $32 \cdot 4$ \\
\hline H200f05_0 & Compression & 0 & 0 & 200 & $0 \cdot 5$ & 0.933 & $636 \cdot 7$ & $1 \cdot 54$ & $37 \cdot 8$ \\
\hline H100f00_15 & Compression + torsion & 15 & $0 \cdot 07$ & 100 & 0 & 0.943 & $219 \cdot 3$ & $1 \cdot 32$ & $33 \cdot 0$ \\
\hline H100f05_15 & Compression + torsion & 15 & $0 \cdot 07$ & 100 & $0 \cdot 5$ & 0.947 & $345 \cdot 0$ & $1 \cdot 68$ & $41 \cdot 4$ \\
\hline H200f00_15 & Compression + torsion & 15 & $0 \cdot 07$ & 200 & 0 & 0.926 & $401 \cdot 2$ & $1 \cdot 26$ & $31 \cdot 5$ \\
\hline H200f05_15 & Compression + torsion & 15 & $0 \cdot 07$ & 200 & $0 \cdot 5$ & 0.937 & $552 \cdot 7$ & $1 \cdot 51$ & $37 \cdot 4$ \\
\hline H100f00_30 & Compression + torsion & 30 & $0 \cdot 25$ & 100 & 0 & $0 \cdot 950$ & $168 \cdot 8$ & $1 \cdot 20$ & $33 \cdot 1$ \\
\hline H100f05_30 & Compression + torsion & 30 & $0 \cdot 25$ & 100 & $0 \cdot 5$ & 0.941 & $216 \cdot 2$ & $1 \cdot 48$ & $41 \cdot 3$ \\
\hline H200f00_30 & Compression + torsion & 30 & $0 \cdot 25$ & 200 & 0 & 0.945 & $295 \cdot 0$ & $1 \cdot 16$ & $31 \cdot 4$ \\
\hline H200f05_30 & Compression + torsion & 30 & $0 \cdot 25$ & 200 & $0 \cdot 5$ & 0.943 & $379 \cdot 3$ & $1 \cdot 37$ & $37 \cdot 6$ \\
\hline H100f00_45 & Torsion & 45 & $0 \cdot 50$ & 100 & 0 & 0.958 & $102 \cdot 3$ & $1 \cdot 02$ & $32 \cdot 4$ \\
\hline H100f05_45 & Torsion & 45 & $0 \cdot 50$ & 100 & $0 \cdot 5$ & 0.953 & $126 \cdot 3$ & $1 \cdot 20$ & $39 \cdot 7$ \\
\hline H200f00_45 & Torsion & 45 & $0 \cdot 50$ & 200 & 0 & 0.940 & $193 \cdot 7$ & $0 \cdot 96$ & $29 \cdot 9$ \\
\hline H200f05_45 & Torsion & 45 & $0 \cdot 50$ & 200 & $0 \cdot 5$ & 0.934 & $212 \cdot 7$ & $1 \cdot 04$ & $33 \cdot 1$ \\
\hline H100f00_60 & Extension + torsion & 60 & $0 \cdot 75$ & 100 & 0 & 0.932 & $86 \cdot 4$ & $1 \cdot 02$ & $36 \cdot 7$ \\
\hline H100f05_60 & Extension + torsion & 60 & $0 \cdot 75$ & 100 & $0 \cdot 5$ & 0.956 & $94 \cdot 6$ & $1 \cdot 07$ & $39 \cdot 7$ \\
\hline H200f00_60 & Extension + torsion & 60 & $0 \cdot 75$ & 200 & 0 & 0.938 & $151 \cdot 9$ & $0 \cdot 87$ & $30 \cdot 6$ \\
\hline H200f05_60 & Extension + torsion & 60 & $0 \cdot 75$ & 200 & $0 \cdot 5$ & 0.931 & $185 \cdot 4$ & $1 \cdot 02$ & $35 \cdot 7$ \\
\hline H100f00_90 & Extension & 90 & 1 & 100 & 0 & 0.946 & $72 \cdot 9$ & $0 \cdot 97$ & $35 \cdot 2$ \\
\hline H100f05_90 & Extension & 90 & 1 & 100 & $0 \cdot 5$ & 0.955 & $75 \cdot 9$ & $1 \cdot 00$ & $36 \cdot 7$ \\
\hline H200f00_90 & Extension & 90 & 1 & 200 & 0 & 0.946 & $136 \cdot 9$ & $0 \cdot 88$ & $31 \cdot 1$ \\
\hline H200f05_90 & Extension & 90 & 1 & 200 & $0 \cdot 5$ & 0.933 & $141 \cdot 3$ & $0 \cdot 91$ & $32 \cdot 3$ \\
\hline
\end{tabular}

Note: as inner and outer confining pressures are identical $\left(p_{\mathrm{i}}^{\prime}=p_{\mathrm{o}}^{\prime}\right), b$ and $\alpha_{\sigma}$ are related through the relation: $b=2 \sin ^{2} \alpha_{\sigma}$.

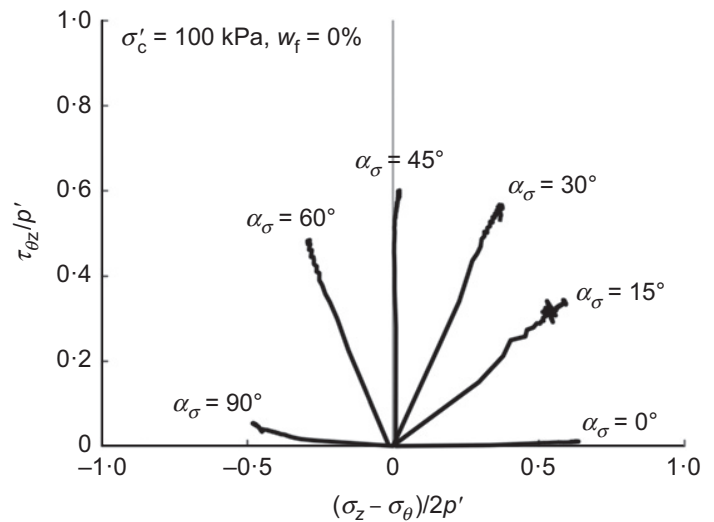

(a)

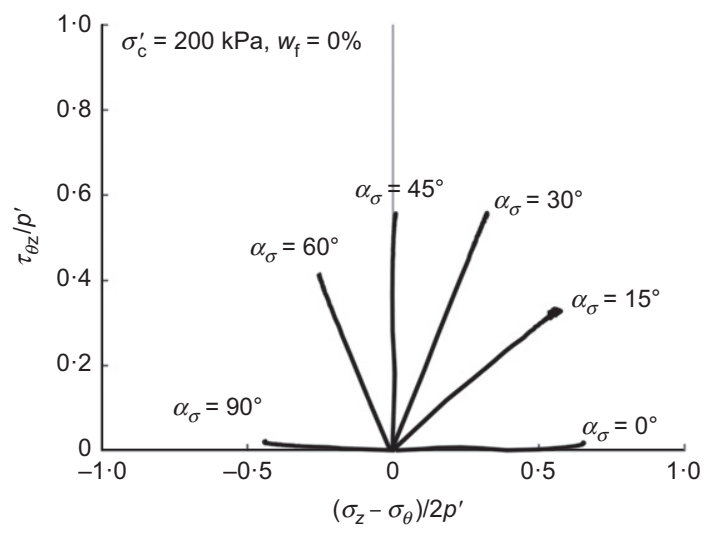

(c)

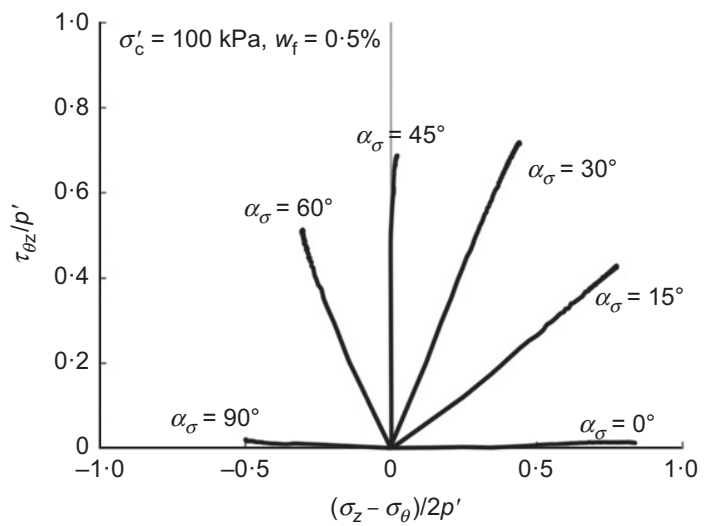

(b)

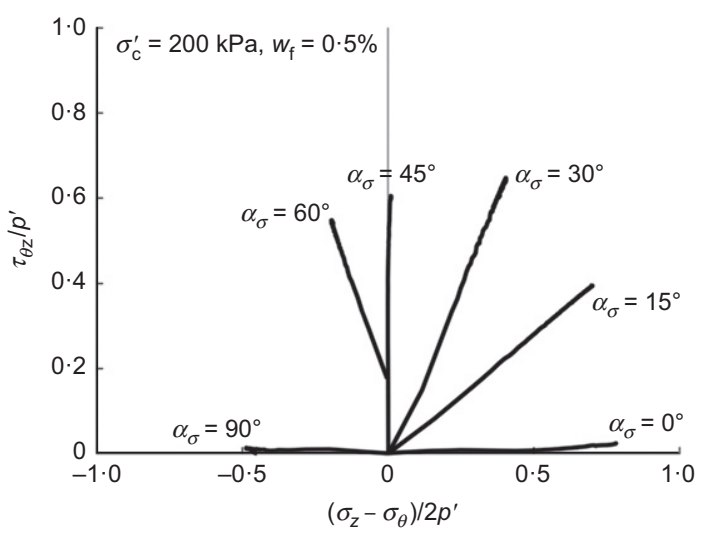

(d)

Fig. 4. Imposed stress paths for: (a) and (c) unreinforced specimens; (b) and (d) reinforced specimens under both confining pressures $100 \mathrm{kPa}$ (top figures) and $200 \mathrm{kPa}$ (bottom figures)

consequence of the reduction of the mean effective stress $\left(p^{\prime}\right)$ at failure. The addition of fibres results in a deviatoric strength increase which, as expected, is progressive with the increase of the deviatoric strains during each test. However, the strengthening contribution of fibres decreases with increasing $\alpha_{\sigma}$. These results corroborate well with the 


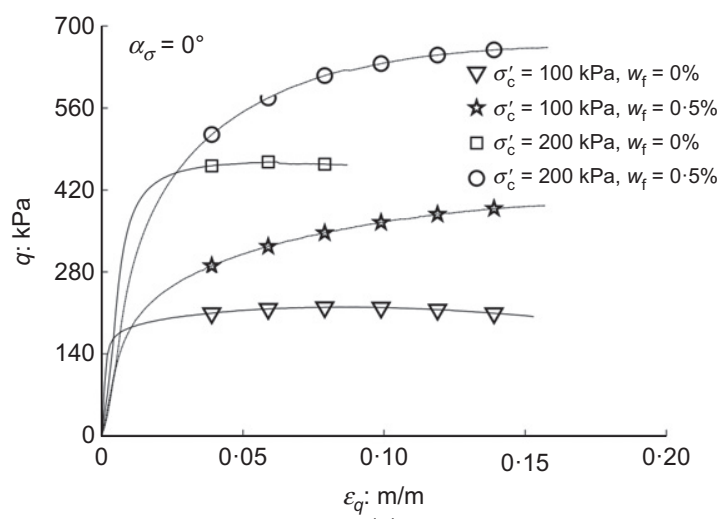

(a)

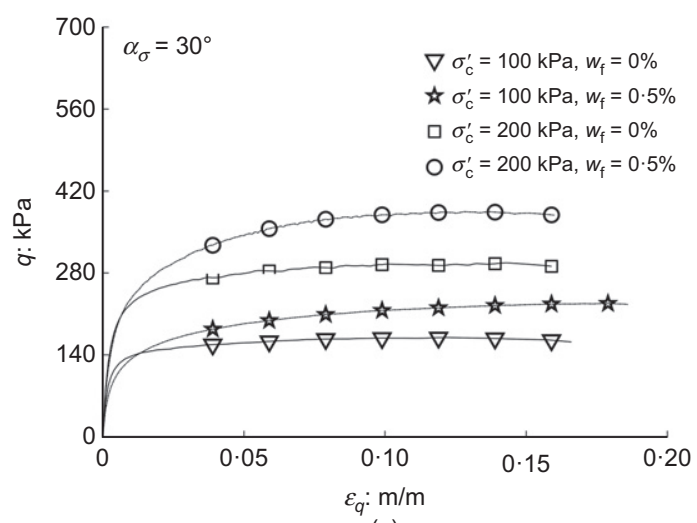

(c)

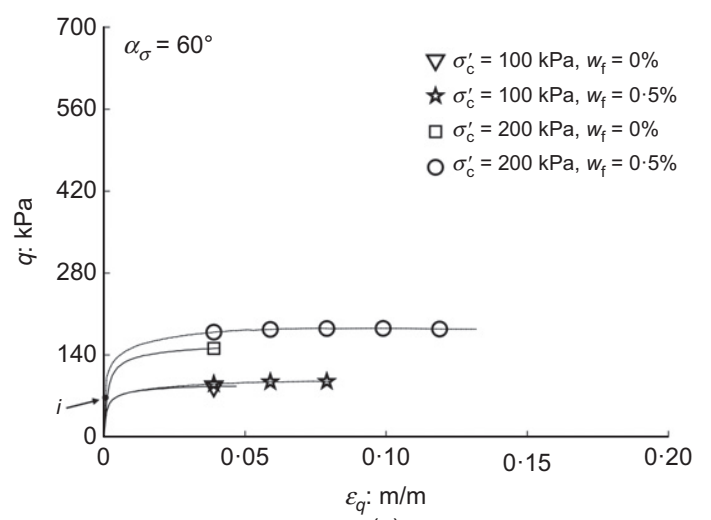

(e)

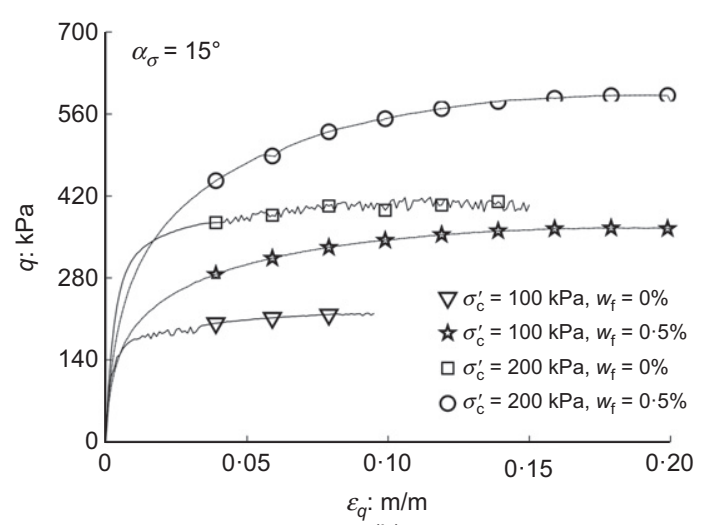

(b)

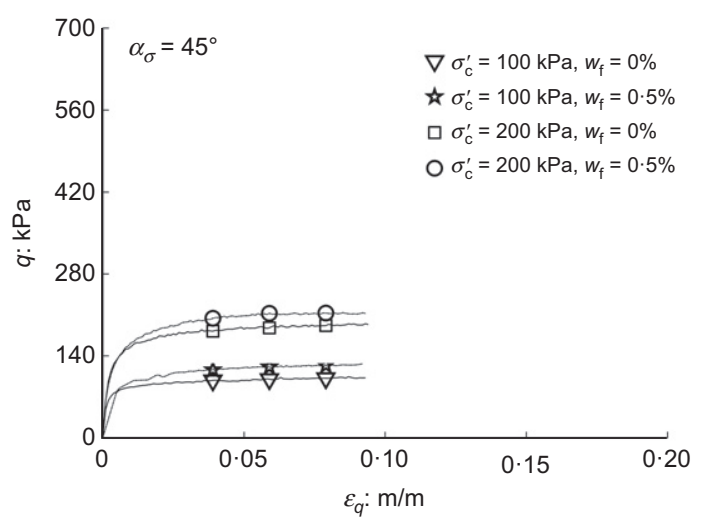

(d)

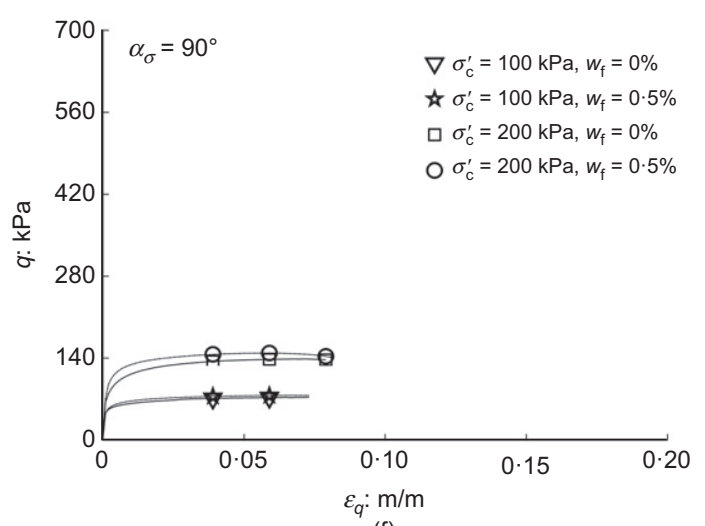

(f)

Fig. 5. Deviatoric stress-strain $\left(q-\varepsilon_{q}\right)$ comparison between unreinforced and reinforced specimens for similar value of $\alpha_{\sigma}$ and for both confining pressures. Note that ' $i$ ' in Fig. 5(e) is the point from which the test $\mathrm{H200f05}$ was switched from $\alpha_{\sigma}=45^{\circ}$ to $60^{\circ}$

observations from triaxial compression and extension tests performed by Diambra et al. (2010). While the fibre strengthening contribution is certainly influenced by different mean effective stresses, $p^{\prime}$, at failure for the different probing paths, the addition of fibres produces about $67 \%$ and $38 \%$ strength increase at $10 \%$ deviatoric strain for the $\alpha_{\sigma}=0^{\circ}$ probing stress path at 100 and $200 \mathrm{kPa}$ cell confining pressure, respectively, and only about $4 \%$ and $3 \%$ for $\alpha_{\sigma}=90^{\circ}$ at the same deviatoric strain level and confining pressure conditions.

The deviatoric strength difference between the reinforced and unreinforced specimens at a representative deviatoric strain of $10 \%, \Delta q_{10}$, is plotted against the imposed rotation of the principal stress axes, $\alpha_{\sigma}$, in Fig. 6. For both applied confining pressures, the net fibre strength contribution $\Delta q_{10}$ decreases at a lower rate for $\alpha_{\sigma}$ values up to $15-20^{\circ}$, and then at a much higher rate up to a value of $\alpha_{\sigma}=45^{\circ} . \Delta q_{10}$ becomes almost negligible for $\alpha_{\sigma}$ ranging between $60^{\circ}$ and $90^{\circ}$.
Previous studies (Michałowski \& Čermák, 2002; Diambra et al., 2010) suggested that the fibre strengthening effect is affected by the fibre orientation distribution in relation with the tensile strains domain developed in the sample, as the strength of only those fibres oriented along tensile strain directions will be mobilised. Ibraim et al. (2012) demonstrated that cylindrical moist vibrated fibre-reinforced specimens fabricated with the same sand and slightly longer fibres present a stronger horizontal fibre bedding: more than $80 \%$ of fibres are oriented within $\pm 45^{\circ}$ of the horizontal plane. Although the fibre orientation distribution has not been assessed for hollow cylindrical samples, it is conceivable that most of the fibres will still tend to lie horizontally. If the components of the strains on the horizontal plane $\left(\varepsilon_{\mathrm{r}}\right.$ and $\left.\varepsilon_{\theta}\right)$ are plotted against $\alpha_{\sigma}$ alongside $\Delta q_{10}$ in Fig. 6, all three variables appear to be related through a similar trend. By increasing $\alpha_{\sigma}$, the tensile principal strain directions gradually rotate towards the vertical direction, and the stretched 


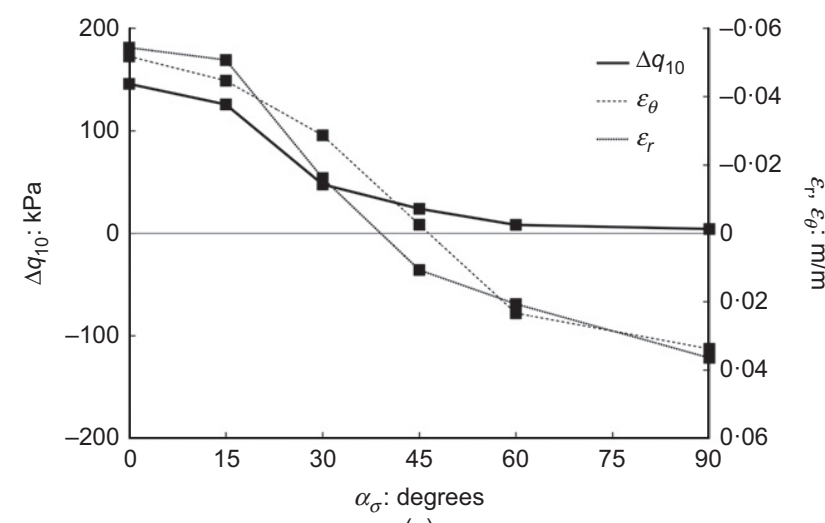

(a)

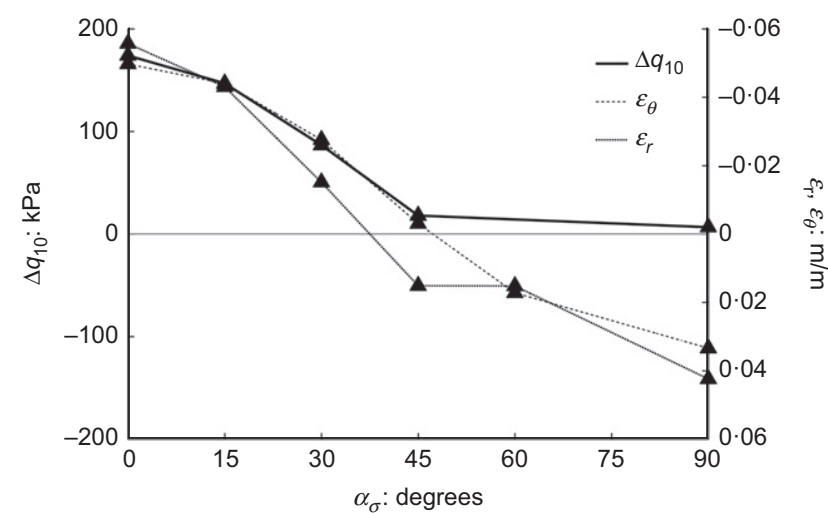

(b)

Fig. 6. Comparison of the radial and circumferential strains $\left(\varepsilon_{\mathrm{r}}\right.$ and $\varepsilon_{\theta}$ respectively) and the variation of deviatoric stress $\left(\Delta q_{10}\right)$ with the rotation of principal stress $\left(\alpha_{\sigma}\right)$ for the confining pressure of: (a) $100 \mathrm{kPa}$; (b) $200 \mathrm{kPa}$

amount of fibres (mostly horizontally oriented) is expected to decrease. The residual small increase in strength $\left(\Delta q_{10}>0\right)$ for $\alpha_{\sigma}>50^{\circ}-55^{\circ}$ may be caused by either a few fibres still pulled in tension by local grain rearrangements or by a small densification effect induced by the fibre addition.

Volumetric response. The volumetric response, $\varepsilon_{\mathrm{v}}$, plotted against the deviatoric strain, $\varepsilon_{q}$, for the performed tests are all reported in Fig. 7. The volumetric trends of all unreinforced samples show initial contraction followed by some limited dilation for larger value of deviatoric strain $\varepsilon_{q}$. The addition of fibres invariably results in a less contractive and more dilative volumetric response. The increased dilatancy associated with the addition of fibres can be explained by both the slightly higher density of fibre-reinforced samples and by an apparent densification of the sand matrix induced by the presence of fibre, as suggested by the constitutive modelling developments proposed by Diambra et al. (2013), Diambra \& Ibraim (2014) and Muir Wood et al. (2016).

The mobilised angle of dilatancy $(\psi)$ is defined here from the ratio of incremental volumetric and deviatoric strains as follows

$$
\tan \psi=-\frac{\dot{\varepsilon_{\mathrm{v}}}}{\dot{\dot{\varepsilon}_{q}}}
$$

The maximum dilatancy angle $\left(\tan \psi_{\max }\right)$ plotted against the imposed principal stress direction, $\alpha_{\sigma}$, is reported in Fig. 8. Irrespective of the amount of reinforcement and confining pressure, the results show a rather similar concave variation with a minimum for an $\alpha_{\sigma}$ value of about $45^{\circ}$. Although $\tan \psi_{\max }$ should be larger for lower confining pressure levels, data for three pairs of tests (reinforced samples tested at $\alpha_{\sigma}$ of $0^{\circ}$ and $90^{\circ}$, and unreinforced samples with $\alpha_{\sigma}=15^{\circ}$ ) show different trends, perhaps due to the differences in their initial densities.

Principal stress and principal strain increments directions. The coaxiality between the principal stress and principal strain increment directions, $\alpha_{\sigma}$ and $\alpha_{\delta \varepsilon}$, respectively, for both reinforced and unreinforced samples during shearing at different imposed $\alpha_{\sigma}$ is also explored. Trends for all of the tests performed are reported in Fig. 9, where the $y$-axis shows the deviator stress $(q)$, and the $x$-axis shows the principal strain increment direction $\left(\alpha_{\delta \varepsilon}\right)$. The imposed principal stress directions are also shown by dashed lines. As expected, there is a quasi-perfect coaxiality for the tests with imposed $\alpha_{\sigma}=0^{\circ}$ and $90^{\circ}$ for both unreinforced and fibre-reinforced samples (Symes et al., 1988; Cai et al., 2013). For all the other tests, regardless of fibre content or confinement pressure, noncoaxiality between the principal stress and principal strain increment directions is observed during the early stages of the shearing. The angle difference, especially for tests at $\alpha_{\sigma}=15^{\circ}$, $30^{\circ}$ and $60^{\circ}$, can reach values up to about $15^{\circ} . \alpha_{\delta \varepsilon}$ is higher than the imposed principal stress direction for the tests at $\alpha_{\sigma}=15^{\circ}$ and $30^{\circ}$, whereas for the tests at $\alpha_{\sigma}=60^{\circ}$ it is smaller, as also observed by Cai et al. (2013). However, as the shearing advances, $\alpha_{\delta \varepsilon}$ gradually evolves and the noncoaxiality reduces, and a coaxial condition is reached towards the failure (Ibraim et al., 2010). The lack of any visible effect of the fibres on the stress/strain increment coaxiality may suggest that the overall deformation pattern of reinforced soils is mainly governed by the sand matrix.

Deviatoric strength envelopes and mobilised friction angles. Comparison of the deviatoric strength envelopes for both reinforced and unreinforced materials in the normalised stress plane $\left(\tau / p^{\prime}-\left(\sigma_{z}-\sigma_{\theta}\right) / 2 p^{\prime}\right)$ are shown in Fig. 10. The deviatoric strength envelopes for the unreinforced specimens can be well approximated by the Matsuoka-Nakai failure envelope (Matsuoka \& Nakai, 1974) using an effective friction angle of $32^{\circ}$. The addition of fibres enlarges and slightly distorts the strength envelope compared with the unreinforced soil case. An analytical solution to describe the strength envelope for the reinforced soil will be developed in the following section.

The net increase of the friction angle $\Delta \phi_{10}^{\prime}$, defined as the difference between the reinforced and unreinforced friction angles at the same $10 \%$ deviatoric strain level $\left(\Delta \phi_{10}^{\prime}=\phi_{10 \mathrm{r}}^{\prime}-\phi_{10 \mathrm{u}}^{\prime}\right)$, plotted against the orientation of the principal stress direction $\alpha_{\sigma}$ for both confining pressures, $100 \mathrm{kPa}$ and $200 \mathrm{kPa}$, is given in Fig. 11. The trends of angle $\Delta \phi_{10}^{\prime}$ for both confining pressures are quite similar: relatively unchanged for $\alpha_{\sigma}$ up to about $30^{\circ}$, followed by a steady decrease for higher angle $\alpha_{\sigma}$ values. The larger increase in the friction angle corresponds to the lower confining pressure. This is related to the fact that the contribution of the fibres is mostly strain dependent; the higher the confining pressure, the lower are the strains developed.

Failure planes and localisation. In most of the tests, the approach towards the failure conditions was accompanied by the development of one or more shear bands defined as a narrow zone of shear strain localisation. In soil mechanics, the interpretation of the shear localisation is traditionally associated with Coulomb's force equilibrium theory, suggesting that the failure occurs at the point of maximum obliquity, in which case the inclination of the shear bands is 


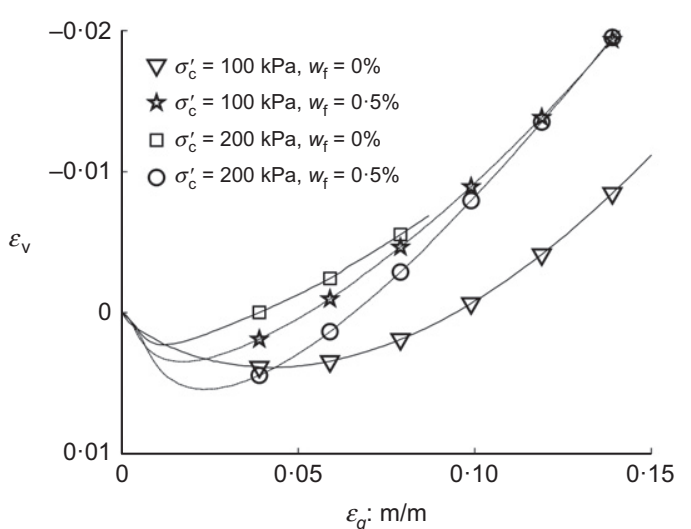

(a)

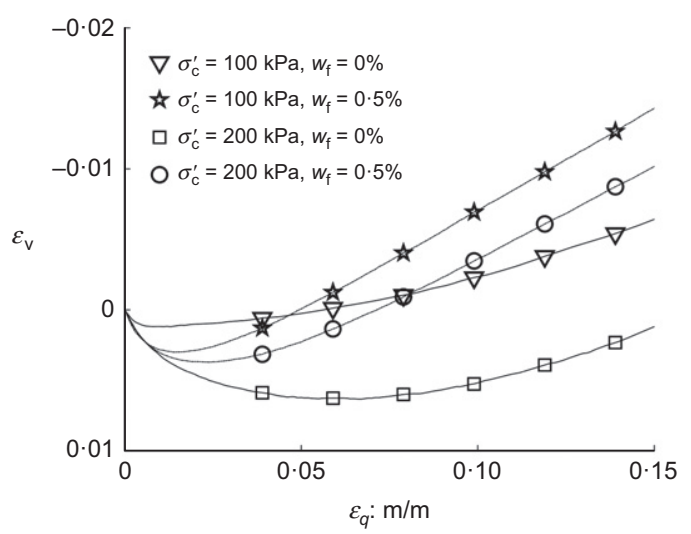

(c)

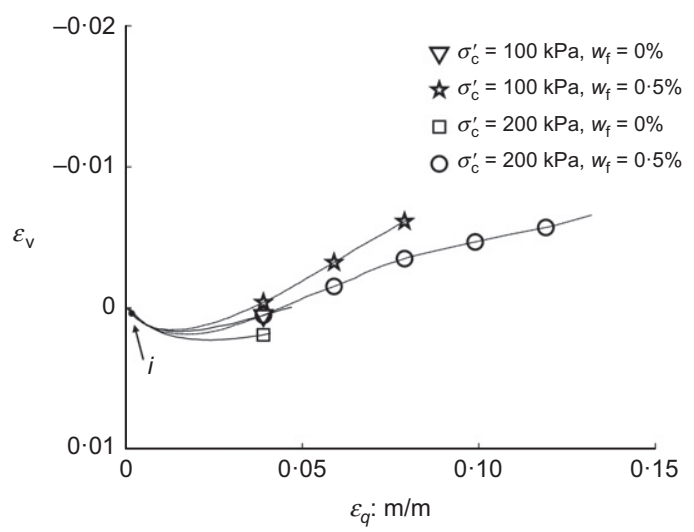

(e)

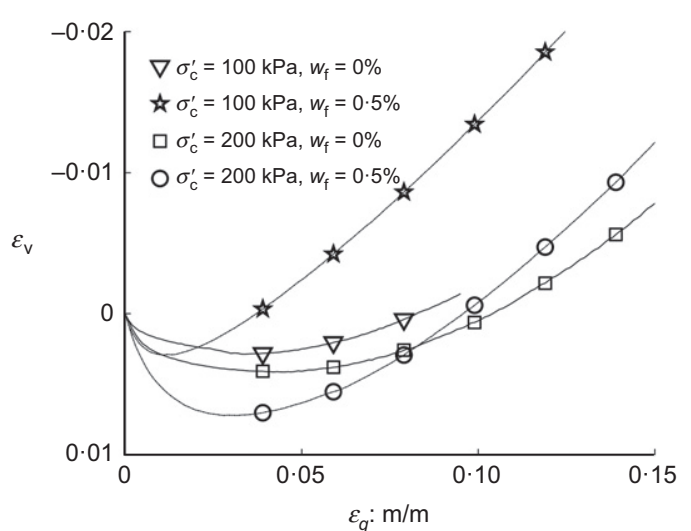

(b)

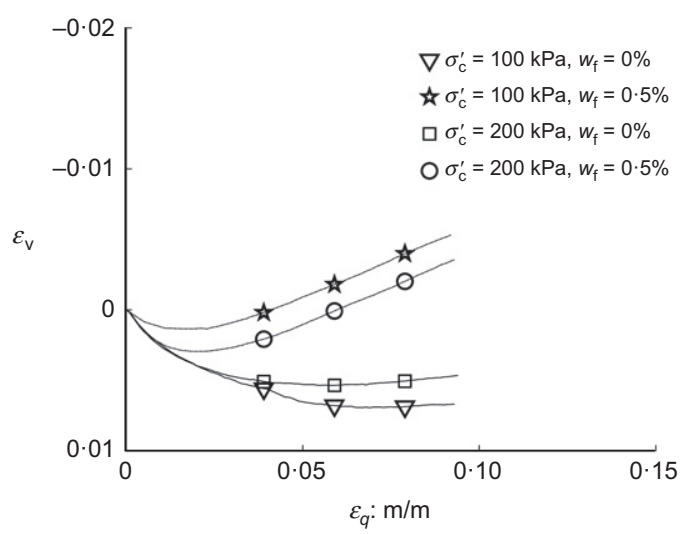

(d)

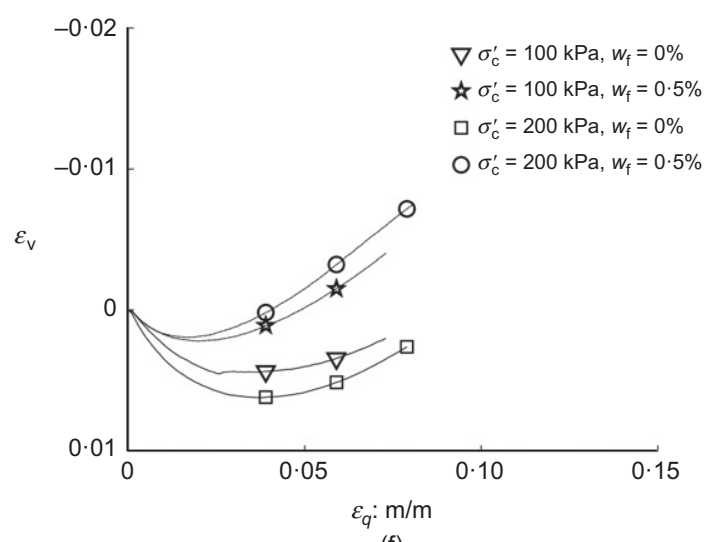

(f)

Fig. 7. Volumetric trends comparison between unreinforced and reinforced specimens for each given $\alpha_{\sigma}$ : (a) $\alpha_{\sigma}=0^{\circ} ;$ (b) $\alpha_{\sigma}=15^{\circ} ;$ (c) $\alpha_{\sigma}=30^{\circ}$; (d) $\alpha_{\sigma}=45^{\circ}$; (e) $\alpha_{\sigma}=60^{\circ}$; (f) $\alpha_{\sigma}=90^{\circ}$. Note that ' $i$ ' in Fig. 7(e) is the point from which the test $\mathrm{H200f05}$ was switched from $\alpha_{\sigma}=45^{\circ}$ to $60^{\circ}$

associated with those planes on which the shear to normal stress ratio is maximum. Based on the Mohr circle of stresses, the theoretical angle, $\zeta$, between the shear band and the direction of the major principal plane is

$$
\zeta=\frac{\pi}{4}+\phi / 2
$$

The theoretically predicted inclinations of shear bands and those visually observed on the failed HCTA samples at the end of the tests (Fig. 12) are listed in Table 5 and a comparison is shown in Fig. 13. The shear band directions were measured at the end of the tests and photographic successive records were taken during the shearing for some specimens. Fig. 12 shows pictures of the unreinforced and reinforced HCTA specimens at the end of the test; the shear bands are indicated by the bold dashed lines. Determination of shear band inclination was conducted directly on the samples after the removal of the HCTA cell. The shear band inclinations for both the theoretical and experimental results appear to match relatively well, with a scatter within a few degrees' difference (see Fig. 13). The only noticeable discrepancy occurs for the tests with imposed $\alpha_{\sigma}=15^{\circ}$ where the predicted inclination of the failure plane is about 12 to $16^{\circ}$ higher than the observed ones. Failure for both unreinforced and reinforced samples tested under triaxial compression conditions $\left(\alpha_{\sigma}=0^{\circ}\right)$ is associated with a specimen bulging and development of shear bands. For triaxial extension $\left(\alpha_{\sigma}=90^{\circ}\right)$, a considerable necking can be observed, but shear bands cannot be visually observed. As a general observation, the addition of fibres does not appear to affect the mode of failure of the sample as well as the orientation of the shear bands. However, the number of shear bands in the fibre-reinforced specimens appears to be higher. The thickness of the shear bands seems also to be smaller when fibres 


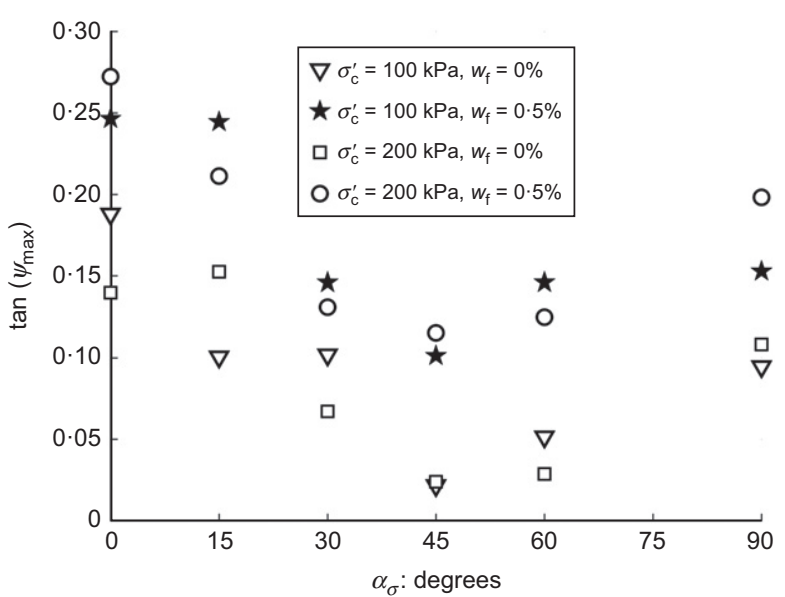

Fig. 8. Trends of maximum dilation angle $\left(\tan \psi_{\max }\right)$ plotted against the imposed direction of the principal stress axis $\left(\alpha_{\sigma}\right)$

are present. For the tests performed at $\alpha_{\sigma}=60^{\circ}$, it is clear that the fibres avoid the formation of a very thick shear band. Table 5 presents the estimation of the shear band thicknesses $\left(t_{\mathrm{fs}}\right)$.

\section{ANALYTICAL PREDICTION OF STRENGTH \\ ENVELOPE FOR FIBRE-REINFORCED SOIL}

An analytical model representing an attempt to predict the deviatoric strength envelope for fibre-reinforced soil in multiaxial stress space is developed and analysed here. The developments account for the effect of the intermediate principal stress and the model can be applied in the generic $\left(\tau / p^{\prime}-\left(\sigma_{z}-\sigma_{\theta}\right) / 2 p^{\prime}\right)$ stress plane. The basis of the relation builds on the superposition of fibres and sand matrix effects. The physical meaning of the constitutive parameters is also explored.

The Matsuoka-Nakai strength criterion (Matsuoka \& Nakai, 1974), which accounts for the magnitude of the intermediate principal stress, has been adopted to reproduce the strength envelope for the unreinforced soil

$$
K=\frac{I_{3}}{I_{1} I_{2}}
$$

where $I_{1}, I_{2}$ and $I_{3}$ are three effective stress invariants and $K$ is defined by the following relation

$$
K=9+8 \tan ^{2} \phi^{\prime}
$$

However, for simulating the deviatoric strength in the usual $\left(\tau / p^{\prime}-\left(\sigma_{z}-\sigma_{\theta}\right) / 2 p^{\prime}\right)$ plot HCTA test conditions, it would be more appropriate to express the Matsuoka-Nakai criterion function of $\tau_{\max }, p^{\prime}$ and $b$ set of stress invariants, defined by the equations (5), (1) and (4), respectively. The following cubical relationship for the failure criterion results

$$
\begin{gathered}
\frac{8}{9} K\left(\frac{2}{3} b^{3}-b^{2}-b+\frac{2}{3}\right)\left(\frac{\tau_{\max }}{p^{\prime}}\right)^{3}+\left(1-\frac{K}{3}\right) \\
\left(4 b^{2}-4 b+4\right)\left(\frac{\tau_{\max }}{p^{\prime}}\right)^{2}+K-9=0
\end{gathered}
$$

where $b=2 \sin ^{2} \alpha_{\sigma}$ applies for the boundary conditions $p_{\mathrm{i}}^{\prime}=p_{\mathrm{o}}^{\prime}$ imposed in the experimental programme of this research. It follows that equation (14) offers a direct link between the ratio $\tau_{\max } / p^{\prime}$ and the angle $\alpha_{\sigma}$ (through $b$ ). Thus, by solving equation (14), it is now possible to plot the Matsuoka-Nakai strength envelope in the required $\left(\tau / p^{\prime}-\left(\sigma_{z}-\sigma_{\theta}\right) / 2 p^{\prime}\right)$ stress

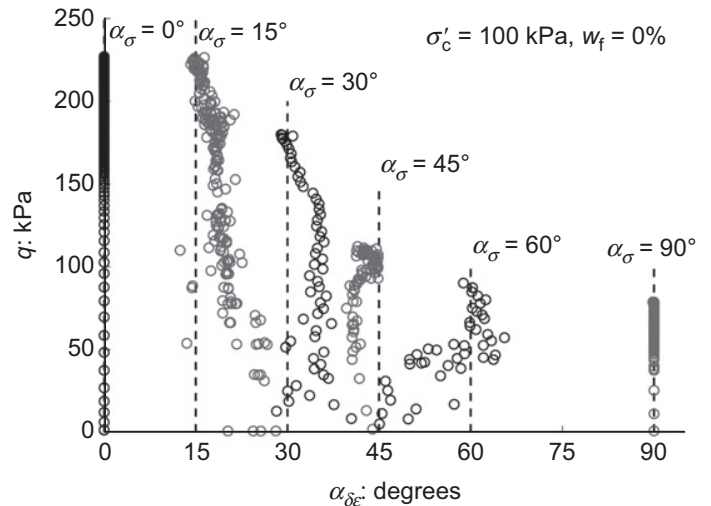

(a)

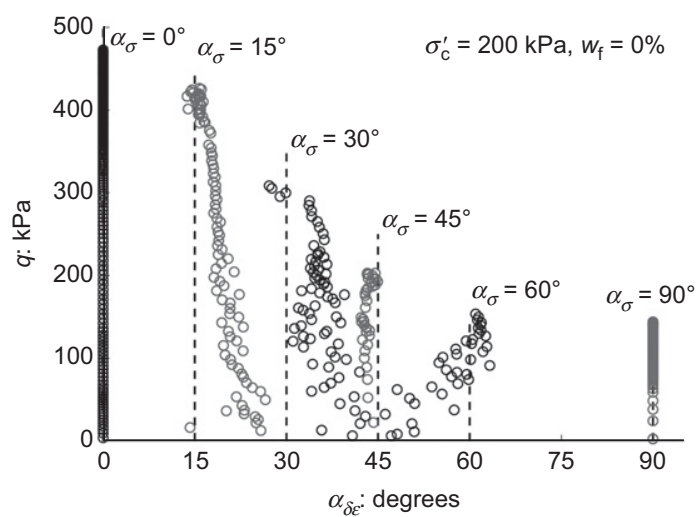

(c)

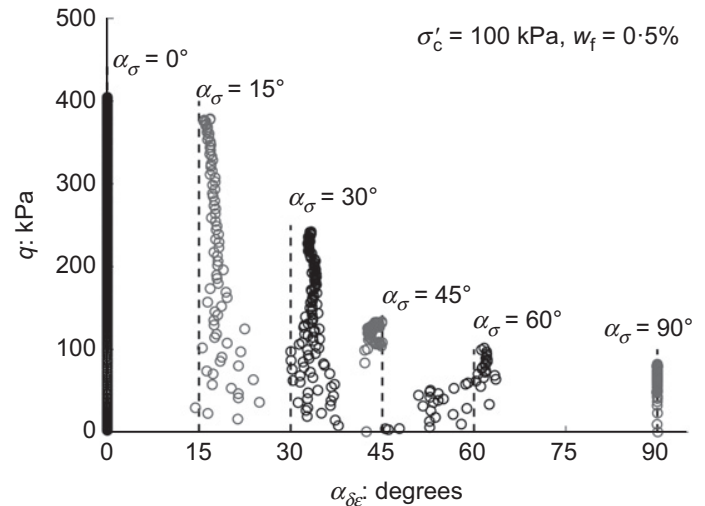

(b)

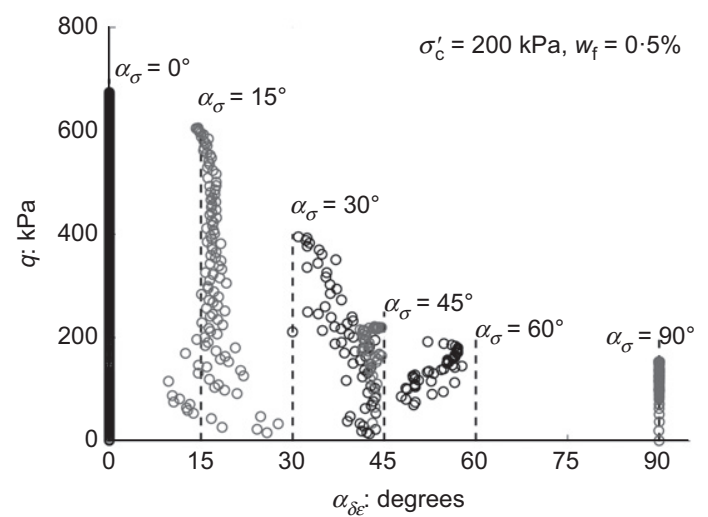

(d)

Fig. 9. Directions of principal stress and strain increments plotted against imposed deviatoric stress: (a) and (c) unreinforced samples at cell confining pressures of 100 and $200 \mathrm{kPa}$, respectively; (b) and (d) fibre-reinforced samples at cell confining pressures of $100 \mathrm{kPa}$ 


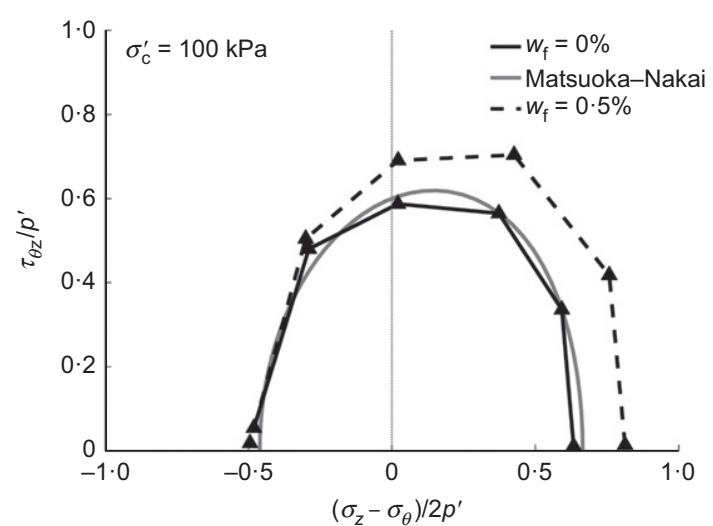

(a)

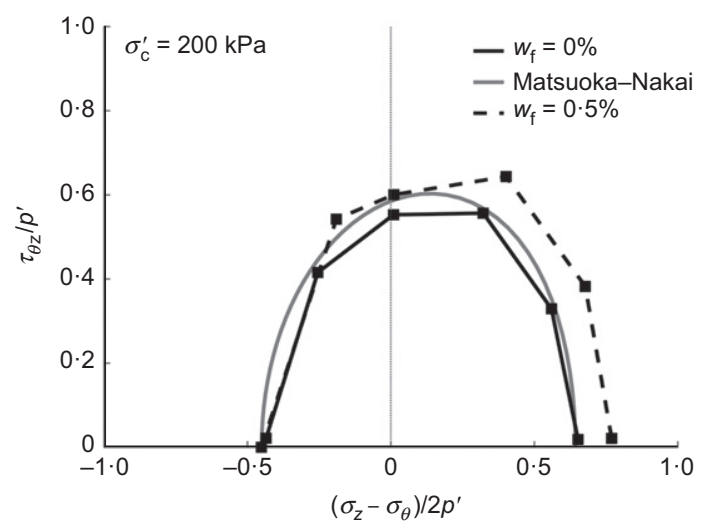

(b)

Fig. 10. Matsuoka-Nakai (Matsuoka \& Nakai, 1974) failure envelope (grey line) with experimental strength envelopes, for unreinforced (solid line) and reinforced samples (dotted line), plotted considering the stress state at $\varepsilon_{q}=10 \%$ for samples under: (a) $100 \mathrm{kPa}$; (b) $200 \mathrm{kPa}$

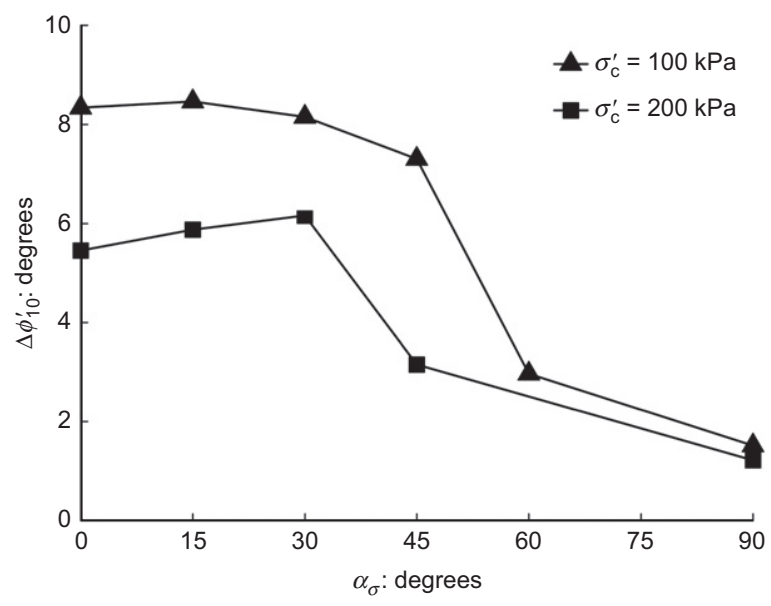

Fig. 11. Variation of the friction angle (at $\varepsilon_{q}=10 \%$ ) between reinforced and unreinforced samples for different $\alpha_{\sigma}$ angles

plane. For typical values of the mobilised friction angle for sands, equation (14) has three real roots: the bigger solution must be selected for $\alpha_{\sigma}>45^{\circ}$ and the intermediate solution for $\alpha_{\sigma}<45^{\circ}$.

The ratio $\tau_{\max } / p^{\prime}$ is an expression of the shear strength of the material. Following approaches in the published literature (Zornberg, 2002; Diambra et al., 2013, 2017; Festugato et al., 2018), superposition of sand matrix and fibre effects can be employed to obtain an expression for the strength envelope of fibre-reinforced soil of the following form

$$
\frac{\tau_{\max } \mathrm{R}}{p^{\prime}}=\frac{\tau_{\max }+R_{\mathrm{f}}}{p^{\prime}}
$$

where $\tau_{\operatorname{maxR}}$ is the radius of the Mohr's circle for the reinforced soil, while $R_{\mathrm{f}}$ is the additional shear strength contribution of the fibres. It is somewhat intuitive to assume that the shear strength contribution of the fibres is dependent on the amount of fibres which are effectively mobilised (or stretched) during a specific shearing test. Thus, introducing $r_{\mathrm{f}}$, the shear strength contribution per unit fibre volume, it is possible to further write

$$
\frac{\tau_{\max } \mathrm{R}}{p^{\prime}}=\frac{\tau_{\max }+\chi \mu_{\mathrm{f}} r_{\mathrm{f}}}{p^{\prime}}
$$

where $\mu_{\mathrm{f}}$ is the total volumetric concentration of fibres and $\chi$ is the proportion of fibres having orientations within the tensile strain domain (proportion of mobilised fibres). Equation (16) can then be rewritten as

$$
\frac{\tau_{\max } \mathrm{R}}{p^{\prime}}=\frac{\tau_{\max }}{p}\left(1+\chi \mu_{\mathrm{f}} \frac{r_{\mathrm{f}}}{\tau_{\max }}\right)
$$

This expression can now be employed to predict the experimental data, imposing a friction angle $\phi^{\prime}=32^{\circ}$ for the unreinforced soil matrix according to the Matsuoka-Nakai strength criterion (see Fig. 10). The proportion of mobilised fibres $\chi$ can be back-calculated from the experimental data by integration of the fibre orientation distribution found by Ibraim et al. (2012) within the tensile strain domain for each HCTA test condition. In this procedure, the experimentally recorded values of axial, radial and shear strains at failure $\left(\varepsilon_{q}=10 \%\right)$ have been used, through the Mohr's circle of strains, to define the aperture and orientation of tensile strain domain for each of the experimental tests performed and the fibre orientation distribution function in equation (18) has been integrated over this angular domain

$$
\rho(\theta)=A+B \cos ^{n}(\theta)
$$

with $A=0, n=6$ and $B=0.3482$ (Diambra et al., 2007; Ibraim et al., 2012). The previous analysis of experimental data in the section entitled 'Principal stress and principal strain increments directions' suggested coaxiality between principal stress and strain rate direction, therefore it was thought convenient to plot the variation of the proportion of fibres $\chi$ as function of the imposed angle $\alpha_{\sigma}$ (Fig. 14), with $93 \%$ of fibres mobilised for $\alpha_{\sigma} \approx 0^{\circ}$ and only about $9 \%$ of all fibres effective for $\alpha_{\sigma} \approx 90^{\circ}$. The linear fit of experimental data has been used in the following calculations.

The comparison between the experimentally determined strength envelope for fibre-reinforced sands and the predictions from equation (17) is shown in Fig. 15. The strengthening contribution per unit fibre content has been calibrated to fit the experimental test data for $\alpha_{\sigma} \approx 0^{\circ}$ to obtain a value of $r_{\mathrm{f}}=3 \cdot 4$. The model predicts well the experimentally determined fibre-reinforced strengths for the other values of $\alpha_{\sigma}$ and reliably captures the overall shape of the fibre-reinforced strength envelope, with a progressively decreasing strengthening effect as $\alpha_{\sigma}$ increases. The importance of considering the real orientation distribution of the fibres and the actual amount of the fibres actively engaged to work in tension can be appreciated by analysing the model predictions if an isotropic distribution of fibre orientation is assumed. In this case, the fibre orientation distribution function is independent of the angle $\theta(\rho(\theta)=\pi / 2)$ and the parameter $\chi$ varies slightly with $\alpha_{\sigma}$ decreasing from 0.59 to 0.42 . Therefore, for an isotropic fibre orientation, the fibre strengthening 


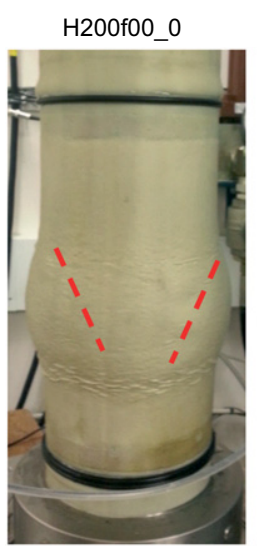

H200f05_0

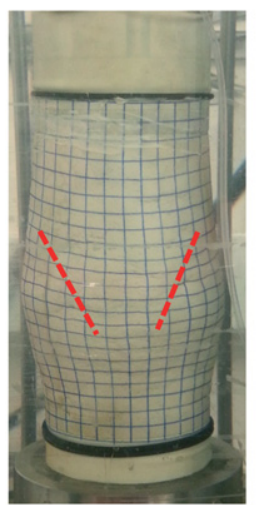

H200f00 15

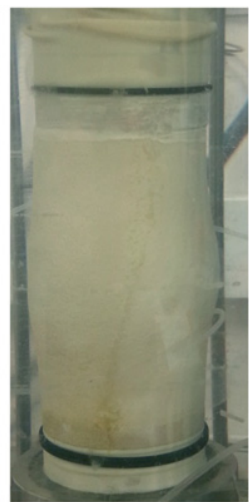

H200f05_15

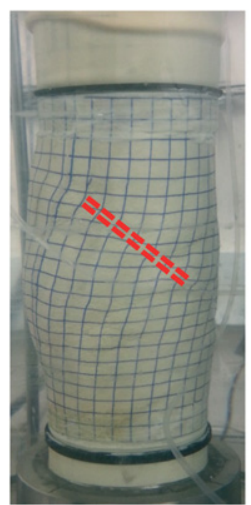

H200f00_30

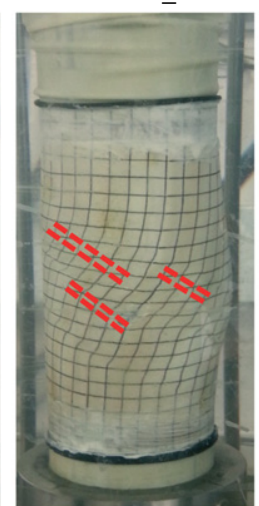

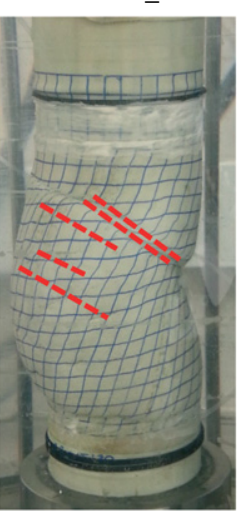

H200f00_45

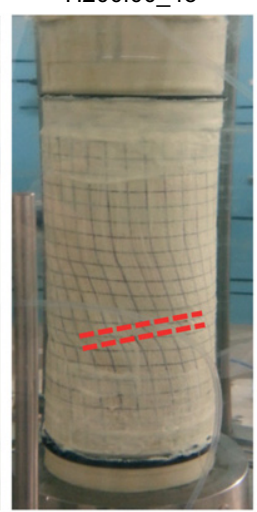

(a)
H200f00_60

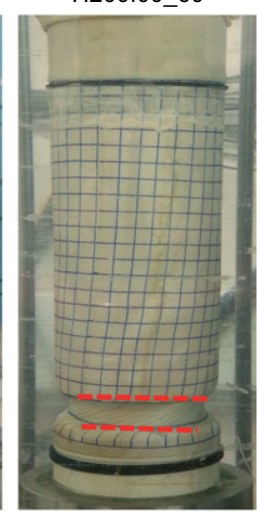

H200f05_60
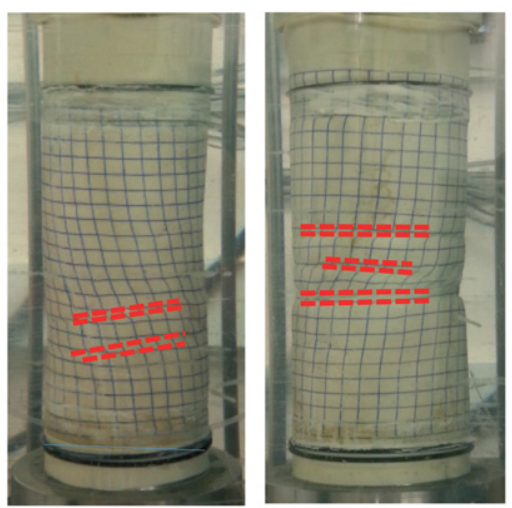

H200f00_90

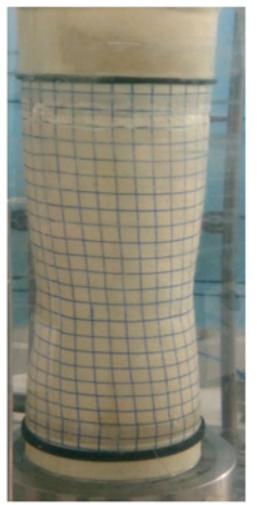

H200f05_90

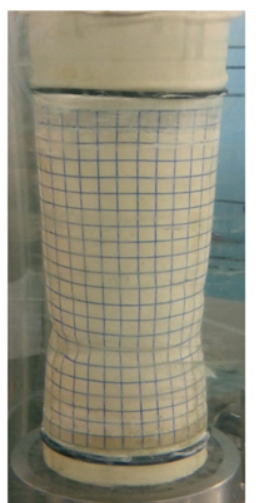

(b)

Fig. 12. Pictures of (a) unreinforced and (b) reinforced specimens at the end of shearing

Table 5. Comparison between theoretically determined $(\zeta)$ and observed orientation $\left(\zeta_{\text {obs }}\right)$ of the failure planes in the tested specimens. Thickness $\left(t_{\mathrm{fs}}\right)$ and brief description of the experimental failure planes are also reported

\begin{tabular}{|c|c|c|c|c|c|c|}
\hline \multirow[t]{2}{*}{ Test name } & \multirow[t]{2}{*}{$\alpha_{\sigma}: \operatorname{deg}$} & \multicolumn{2}{|c|}{ Mohr-Coulomb } & \multicolumn{3}{|c|}{ Visual observation } \\
\hline & & $\phi_{\text {fail }}^{\prime}: \operatorname{deg}$ & $\zeta: \operatorname{deg}$ & $\zeta_{\text {obs }}{ }^{*}: \operatorname{deg}$ & $t_{\mathrm{fs}}: \mathrm{mm}$ & Description \\
\hline H100f00_0 & 0 & $31 \cdot 7$ & $60 \cdot 8$ & 65 & 1 to 3 & Bulging and one failure plane \\
\hline H100f00_15 & 15 & $33 \cdot 0$ & $61 \cdot 5$ & - & & Not identified \\
\hline H100f00_30 & 30 & $33 \cdot 1$ & $61 \cdot 5$ & 70 & 4 to 6 & One failure plane \\
\hline H100f00_45 & 45 & $32 \cdot 5$ & $61 \cdot 2$ & - & & Not identified \\
\hline H100f00_60 & 60 & $36 \cdot 7$ & $63 \cdot 4$ & 60 & 30 to 40 & One failure plane \\
\hline H100f00_90 & 90 & $35 \cdot 0$ & $62 \cdot 5$ & - & & Necking \\
\hline H100f05_0 & 0 & $41 \cdot 0$ & $65 \cdot 5$ & 64 & 1 to 3 & Bulging and one failure plane \\
\hline H100f05_15 & 15 & $42 \cdot 3$ & $66 \cdot 2$ & 49 & 4 to 5 & One failure plane \\
\hline H100f05_30 & 30 & $42 \cdot 4$ & $66 \cdot 2$ & - & - & Not identified \\
\hline $\mathrm{H} 100 \mathrm{f} 05 \_45$ & 45 & $39 \cdot 8$ & $64 \cdot 9$ & 63 & 2 to 4 & Three failure planes \\
\hline H100f05_60 & 60 & $39 \cdot 7$ & $64 \cdot 8$ & 64 & 5 to 10 & One failure plane \\
\hline H100f05_90 & 90 & $36 \cdot 7$ & $63 \cdot 4$ & - & & Necking \\
\hline H200f00_0 & 0 & $32 \cdot 5$ & $61 \cdot 2$ & 65 & 1 to 3 & Bulging and one failure plane \\
\hline H200f00_15 & 15 & $32 \cdot 0$ & $61 \cdot 0$ & - & & Not identified \\
\hline H200f00_30 & 30 & $31 \cdot 5$ & $60 \cdot 7$ & 65 & 5 to 7 & Three failure planes \\
\hline H200f00_45 & 45 & $30 \cdot 1$ & $60 \cdot 1$ & 57 & 5 to 7 & One failure plane \\
\hline H200f00_60 & 60 & $30 \cdot 6$ & $60 \cdot 3$ & 60 & 20 & One failure plane \\
\hline H200f00_90 & 90 & $31 \cdot 8$ & $60 \cdot 9$ & - & & Necking \\
\hline H200f05_0 & 0 & $38 \cdot 4$ & $64 \cdot 2$ & 67 & 1 to 3 & Bulging and two failure planes \\
\hline H200f05_15 & 15 & $38 \cdot 6$ & $64 \cdot 3$ & 52 & 3 to 5 & One failure plane \\
\hline H200f05_30 & 30 & $37 \cdot 7$ & $63 \cdot 8$ & 65 & 6 to 8 & Four failure planes \\
\hline H200f05_45 & 45 & $32 \cdot 9$ & $61 \cdot 5$ & 55 & 3 to 6 & Two failure planes \\
\hline H200f05_60 & 60 & $35 \cdot 8$ & $62 \cdot 9$ & 60 & 3 to 8 & Three failure planes \\
\hline H200f05_90 & 90 & $34 \cdot 4$ & $62 \cdot 2$ & - & - & Necking \\
\hline
\end{tabular}

*The observed failure slope inclination $\zeta_{\text {obs }}$ was determined considering clockwise angles as positive. 


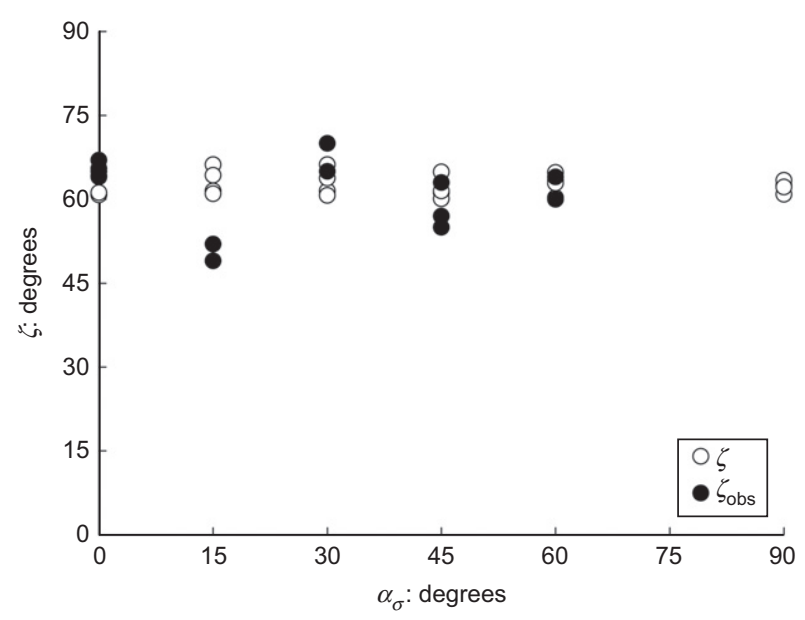

Fig. 13. Theoretical $(\zeta)$ and observed $\left(\zeta_{\text {obs}}\right)$ shear band inclination with respect to the major principal stress direction

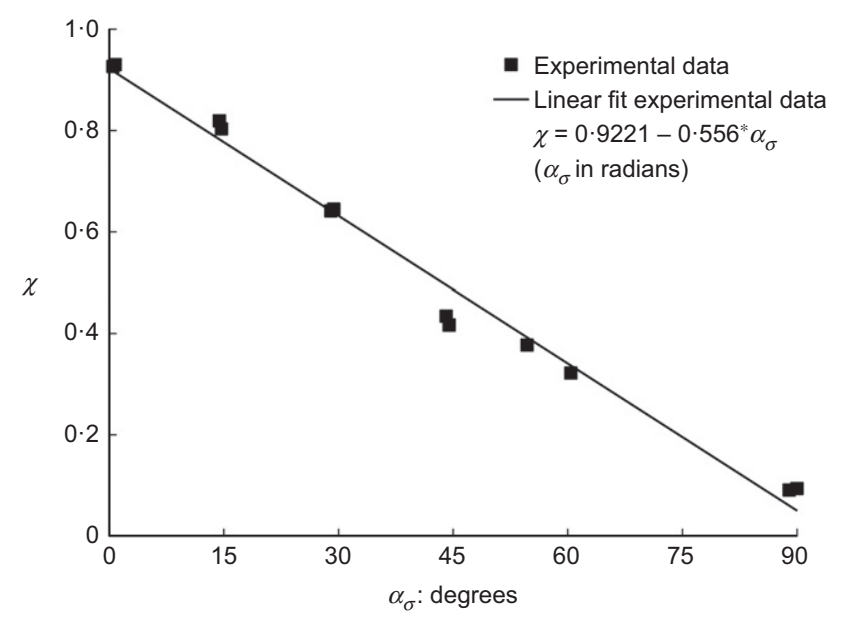

Fig. 14. Proportion of fibres oriented within the tensile strain domain using back-calculation of experimental data

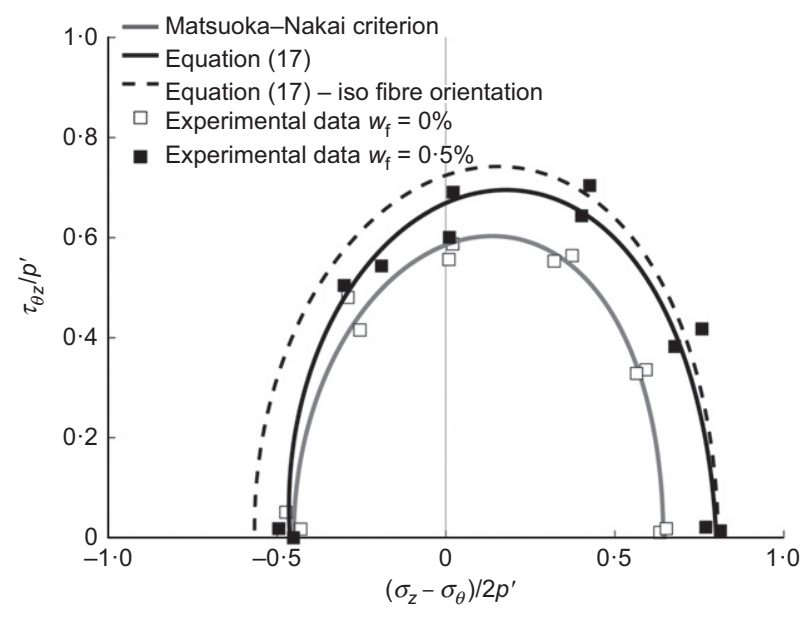

Fig. 15. Theoretical and experimental deviatoric strength envelopes of sand and fibre-reinforced sand

contribution would be almost independent from the orientation of principal stress, $\alpha_{\sigma}$, resulting in an inaccurate prediction of the fibre-reinforced strength envelope, as shown in Fig. 15.

Michałowski (2008) suggested that the strength anisotropy of fibre-reinforced soils is primary related to the imposed strain rate direction during the test, as the contribution of fibres is largely strain driven. Although this is indeed unquestionable, the obtained prediction of the experimental data in Fig. 15 suggests that the use of a single fibre mobilisation parameter (such as $\chi$ ) - governed by the imposed principal stress direction - may provide a simpler alternative with still satisfactory results. However, ideally, a theoretical model which employs two parameters, one governing the contribution per unit volume of fibres and one related to the fibre orientation distribution, like the one proposed in equation (17) should produce satisfactory simulations of the deviatoric strength envelope for fibre-reinforced soils in the multiaxial stress space.

Application of this theoretical model to mixtures of different fibre and soil types will require the determination of the specific fibre orientation distribution and the re-calibration of the parameter $r_{\mathrm{f}}$ describing the strengthening contribution per unit fibre, which is expected to be controlled by the fibre and soil characteristics (e.g. fibre length aspect ratio, fibre to grain size ratio) as well as by the applied stress level conditions.

\section{CONCLUSIONS}

An experimental programme using the HCTA has been undertaken to investigate the strength anisotropy of fibre-reinforced sands in the multiaxial stress space. The experimental programme comprised 24 monotonic drained tests on both unreinforced and fibre-reinforced granular soil specimens, imposing six probing stress paths each with different orientations of the principal stress axis. Orientations varied between triaxial compression $\left(\alpha_{\sigma}=0^{\circ}\right)$ and triaxial extension $\left(\alpha_{\sigma}=90^{\circ}\right)$ conditions, under two equal values of internal and external cell confining pressures. The experimental data provided the following conclusions and points of interest.

(a) Owing to the sample's thin wall, curvature and height, laboratory fabrication of fibre-reinforced hollow cylinder tests proved to be a challenging task. The commonly adopted moist tamping technique did not lead to fabrication of uniform specimens. The moist vibration technique was found to be more suitable. However, it was necessary to mix the soil and fibres in five different portions, in order to ensure a uniform distribution of fibres (which may be compromised by the deposition process inside the mould) and obtain a satisfactory repeatability of experimental results.

(b) For the first time, a deviatoric strength envelope in the multiaxial stress space has been identified for fibre-reinforced soils. Compared to the unreinforced case, which could be reproduced well using the Matsuoka-Nakai strength criterion imposing a friction angle of $32^{\circ}$, the addition of fibres produces an anisotropic response and thus a distortion of the strength envelope.

(c) The contribution of fibres was at a maximum for the imposed stress path at $\alpha_{\sigma}=0^{\circ}$, with a net increase of the friction angle up to $8^{\circ}$; the net increase of the friction angle eventually decreases with the increase of the orientation, $\alpha_{\sigma}$, to reach only about $1^{\circ}$ for $\alpha_{\sigma}=90^{\circ}$. A similar trend for the deviatoric strength increase and mobilised tensile strains in the horizontal plane with the imposed orientation of principal stress axes was observed. Considering that fibre orientation for the tested specimens was expected to be mostly horizontal, the fibre strengthening contribution seems to be 
proportional to the tensile strain developed along their preferred orientation.

(d) For probing stress paths with a direction of the principal stress different from the vertical and horizontal directions, non-coaxiality between principal stress and strain rate directions was observed during the early stages of shearing. Eventually, coaxiality was restored at large strains, close to the failure conditions. Despite the considerable strength contribution, the fibres seemed to have no influence on the coaxiality of stress and strain rates axes, suggesting that the deformation behaviour of fibre-reinforced specimens is mostly governed by the sand matrix.

(e) Addition of fibres was not found to influence the overall mode of failure of the sample and the orientation of localised shear bands. However, it appeared that the addition of fibres increases the number of visible shear bands, while decreasing their thickness. Fibres also prevent the creation of thick failure planes.

( $f$ ) A theoretical model which employs two parameters, one governing the contribution per unit volume of fibres and one relative to the fibre orientation distribution, was developed to describe the failure envelope for fibre-reinforced soils.

It is hoped that the experimental data presented and evidence for the anisotropic failure strength envelope of fibrereinforced sand under a range of monotonic multiaxial histories will help the development of constitutive models formulated in the multiaxial stress space to be used for numerical analyses. It is believed that the proper and accurate account of the anisotropic strength of fibre-reinforced soils is of the utmost importance for geotechnical design in field applications, where rotations of principal stress axes almost invariably occur within a soil mass.

\section{ACKNOWLEDGEMENT}

This work has been supported by the Engineering and Physical Sciences Research Council (EPSRC) grant $\mathrm{EP} / \mathrm{J} 010022 / 1$. All underlying data are provided in full within this paper.

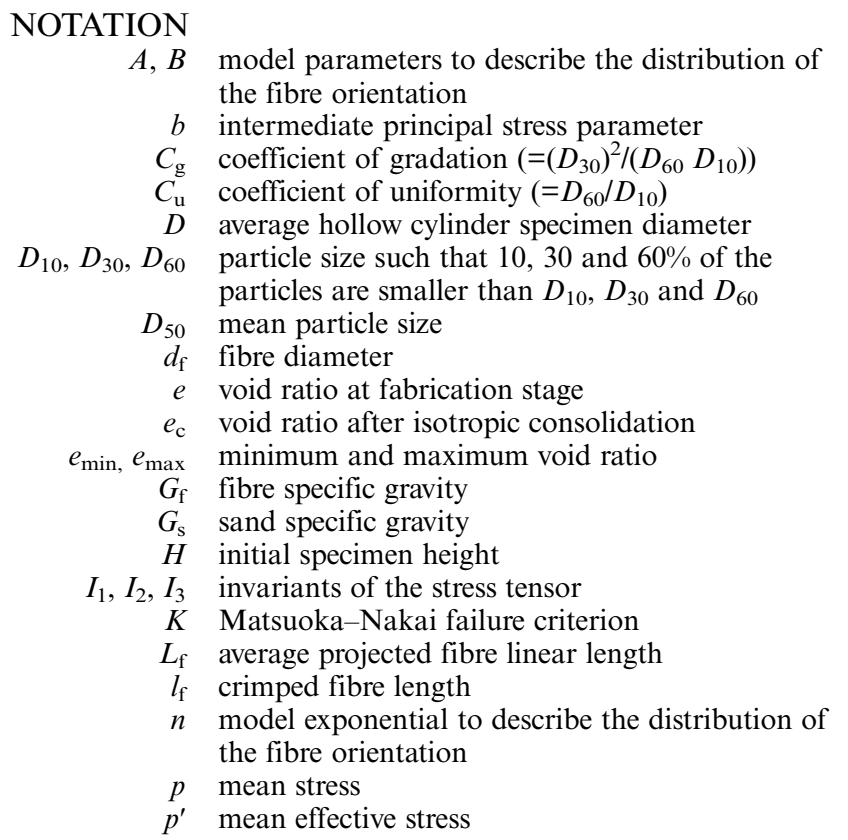

$p_{\mathrm{i}}, p_{\mathrm{o}} \quad$ inner and outer pressure applied to the hollow cylinder specimen

$p_{\mathrm{i}}^{\prime}, p_{\mathrm{o}}^{\prime} \quad$ effective inner and outer pressure applied to the hollow cylinder specimen

$q$ deviatoric stress

$q_{10}$ deviatoric stress at $10 \%$ of deviatoric strain

$R_{\mathrm{f}}$ overall shear strength contribution of the fibres

$r_{\mathrm{f}}$ shear strength contribution per unit volume of fibres

$r_{\mathrm{i}}, r_{\mathrm{o}}$ inner and outer radius of the hollow cylinder specimen

$T$ torque load

$t_{\mathrm{fs}} \quad$ shear band's thickness

$t_{\mathrm{w}} \quad$ wall thickness of the hollow cylinder specimen

$u$ pore water pressure

$W$ axial load

$W_{\mathrm{f}} \quad$ weight of fibres

$W_{\mathrm{s}} \quad$ dry weight of sand

$w_{\mathrm{f}} \quad$ percentage of fibre content $\left(=W_{\mathrm{f}} / W_{\mathrm{s}}\right)$

$\alpha_{\delta \varepsilon}$ direction of the major principal strain increment axis relative to the vertical direction

$\alpha_{\sigma}$ direction of the major principal stress axis relative to the vertical direction

$\gamma_{\theta z} \quad$ circumferential shear deformation $\left(=\gamma_{z \theta}\right)$

$\Delta H \quad$ vertical displacement of the hollow cylinder specimen

$\Delta q_{10} \quad$ variation of deviatoric stress due to fibre addition at $\varepsilon_{q}=10 \%\left(=q_{10 \mathrm{r}}-q_{10 \mathrm{u}}\right)$

$\Delta r_{\mathrm{i}}, \Delta r_{\mathrm{o}} \quad$ variation of inner and outer radius of the hollow cylinder specimen

$\Delta \theta$ variation of rotation angle (relative to the top of the specimen)

$\Delta \phi_{10}^{\prime} \quad$ variation of friction angle due to fibre addition at $\varepsilon_{q}=10 \%\left(=\phi_{10 \mathrm{r}}^{\prime}-\phi_{10 \mathrm{u}}^{\prime}\right)$

$\delta \varepsilon_{z}, \delta \varepsilon_{\theta} \quad$ variation of axial and circumferential deformation

$\delta \gamma_{\theta z} \quad$ variation of circumferential shear deformation

$\varepsilon_{q} \quad$ deviatoric strain component

$\varepsilon_{\mathrm{v}} \quad$ volumetric strain $\left(\varepsilon_{1}+\varepsilon_{2}+\varepsilon_{3}\right)$

$\varepsilon_{z}, \varepsilon_{\mathrm{r}}, \varepsilon_{\theta}$ axial, radial and circumferential deformation

$\dot{\varepsilon}_{q} \quad$ deviatoric strain increment

$\dot{\varepsilon}_{\mathrm{v}} \quad$ volumetric strain increment

$\zeta$ theoretical failure plane inclination with respect to the major principal plane direction

$\zeta_{\text {obs }}$ observed failure plane inclination with respect to the major principal plane direction

$\eta_{\mathrm{f}} \quad$ fibre aspect ratio $\left(=l_{\mathrm{f}} / d_{\mathrm{f}}\right)$

$\eta_{10}$ stress ratio at $10 \%$ of deviatoric strain

$\theta$ fibre orientation from the horizontal plane

$\mu_{\mathrm{f}} \quad$ volumetric concentration of fibre

$\rho(\theta)$ distribution function for fibre orientation

$\sigma_{\mathrm{c}}^{\prime} \quad$ confining cell pressure

$\sigma_{z}, \sigma_{\mathrm{r}}, \sigma_{\theta}$ mean total axial, radial and circumferential stress

$\sigma_{1}, \sigma_{2}, \sigma_{3}$ mean major, intermediate and minor total principal stress

$\tau_{\max }$ maximum shear stress

$\tau_{\operatorname{maxR}}$ maximum shear stress for reinforced soils

$\tau_{\theta z} \quad$ mean circumferential shear stress $\left(=\tau_{z \theta}\right)$

$\phi_{\text {fail }}^{\prime} \quad$ effective friction angle at failure

$\phi_{10}^{\prime}$ effective friction angle at $10 \%$ of deviatoric strain

$\phi_{10 \mathrm{r}}^{\prime}$ effective friction angle at $10 \%$ of deviatoric strain for reinforced samples

$\phi_{10 u}^{\prime}$ effective friction angle at $10 \%$ of deviatoric strain for unreinforced samples

$\chi$ proportion of the engaged fibres

$\psi$ mobilised angle of dilatancy

$\psi_{\max }$ maximum value of mobilised angle of dilatancy

\section{REFERENCES}

Ang, E. C. \& Loehr, J. E. (2003). Specimen size effects for fiber-reinforced silty clay in unconfined compression. Geotech. Testing J. 26, No. 2, 191-200, https://doi.org/10.1520/ GTJ11320J

Arthur, J. R. F., Chua, K. S., Dunstan, T. \& Rodriguez, C. J. I. (1980). Principal stress rotation: a missing parameter. J. Geotech. Engng, ASCE 106, No. 4, 419-433. 
Bostwick, L., Rowe, R. K., Take, W. A. \& Brachman, R. W. I. (2010). Anisotropy and directional shrinkage of geosynthetic clay liners. Geosynthetics Int. 17, No. 3, 157-170.

Cai, Y., Yu, H. S., Wanatowski, D. \& Li, X. (2013). Noncoaxial behavior of sand under various stress paths. J. Geotech. Geoenviron. Eng., ASCE 139, No. 8, 1381-1395, https:/l doi.org/10.1061/(ASCE)GT.1943-5606.0000854.

Diambra, A. (2010). Fibre reinforced sands: experiments and constitutive modelling. $\mathrm{PhD}$ thesis, University of Bristol, Bristol, UK.

Diambra, A. \& Ibraim, E. (2014). Modelling of fibre-cohesive soil mixtures. Acta Geotechnica 9, No. 6, 1029-1043, https:/l doi.org/10.1007/s11440-013-0283-y.

Diambra, A. \& Ibraim, E. (2015). Fibre-reinforced sand: interaction at the fibre and grain scale. Géotechnique 64, No. 4, 296-308, https://doi.org/10.1680/geot.14.P.206.

Diambra, A., Russell, A. R., Ibraim, E. \& Muir Wood, D. (2007). Determination of fibre orientation distribution in reinforced sands. Géotechnique 57, No. 7, 623-628, https://doi.org/10.1680/ geot.2007.57.7.623.

Diambra, A., Ibraim, E., Muir Wood, D. \& Russell, A. R. (2010). Fibre reinforced sands: experiments and modelling. Geotextiles and Geomembranes 28, No. 3, 238-250, https://doi.org/ 10.1016/j.geotexmem.2009.09.010.

Diambra, A., Ibraim, E., Russell, A. R. \& Muir Wood, D. (2013). Fibre reinforced sands: from experiments to modelling and beyond. Int. J. Numer. Analyt. Methods Geomech. 37, 2427-2455, https://doi.org/10.1002/nag.2142.

Diambra, A., Ibraim, E., Peccin, A., Consoli, N. C. \& Festugato, L. (2017). Theoretical derivation of artificially cemented granular soil strength. J. Geotech. Geoenviron. Engng 143, No. 5, 04017003, https://doi.org/10.1061/(ASCE)GT.1943-5606.0001646.

Festugato, L., da Silva, A. P., Diambra, A., Consoli, N. C. \& Ibraim, E. (2018). Modelling tensile/compressive strength ratio of fibre reinforced cemented soils. Geotextiles and Geomembranes 46, No. 2, 155-165.

Gao, Z. \& Zhao, J. (2013). Evaluation on failure of fiber-reinforced sand. J. Geotech. Geoenviron. Engng 139, No. 1, 95-106, https:// doi.org/10.1061/(ASCE)GT.1943-5606.0000737.

Hight, D. W., Gens, A. \& Symes, M. J. (1983). The development of a new hollow cylinder apparatus for investigating the effects of principal rotation in soils. Géotechnique 33, No. 4, 355-383, https://doi.org/10.1680/geot.1983.33.4.355.

Ibraim, E. \& Fourmont, S. (2006). Behaviour of sand reinforced with fibres. In Proceedings of the geotechnical symposium, geomechanics: laboratory testing, modelling and applications, Rome, Italy (eds H. I. Ling, L. Callisto, D. Leshchinsky and J. Koseki), pp. 807-818. Dordrecht, the Netherlands: Springer.

Ibraim, E., Lanier, J., Muir Wood, D. \& Viggiani, G. (2010). Strain path controlled shear tests on an analogue granular material. Géotechnique 60, No. 7, 545-559, https://doi.org/10.1680/ geot.8.P.100

Ibraim, E., Christiaens, P. \& Pope, M. (2011). Development of a hollow cylinder torsional apparatus for pre-failure deformation and large strains behaviour of sand. Geotech. Engng J. of SEAGS \& AGSSEA, Special Issue on Soil Behaviour 42, No. 4, 58-68.
Ibraim, E., Diambra, A., Russell, A. \& Muir Wood, D. (2012). Assessment of laboratory sample preparation for fibre reinforced sands. Geotextiles and Geomembranes 34, 69-79, https:/ /doi.org/10.1016/j.geotexmem.2012.03.002.

Kongkitkul, W., Hirakawa, D., Tatsuoka, F. \& Kanemaru, T. (2007). Effects of geosynthetic reinforcement type on the strength and stiffness of reinforced sand in plane strain compression. Soils Found. 47, No. 6, 1109-1122.

Ling, H. I. \& Tatsuoka, F. (1994). Performance of anisotropic geosynthetic-reinforced cohesive soil mass. J. Geotech. Engng 120, No. 7, 1166-1184.

Mandolini, A. (2012). Triaxial behaviour of fibre-reinforced sands: Influence of the fibre length and grain size. MSc thesis, Università Politecnica delle Marche, Ancona, Italy.

Mandolini, A. (2014). Investigation of strength anisotropy of fibre reinforced sands under generalised loading conditions using the HCTA. MSc thesis, University of Bristol, Bristol, UK.

Matsuoka, H. \& Nakai, T. (1974). Stress-deformation and strength characteristics of soil under three different principal stresses. Proc. Jap. Soc. Civ. Engrs (JSCE) 1974, No. 232, 59-70, https:// doi.org/10.2208/jscej1969.1974.232_59.

Michałowski, R. L. (2008). Limit analysis with anisotropic fiber-reinforced soil. Géotechnique 58, No. 6, 489-501, https://doi.org/10.1680/geot.2008.58.6.489.

Michałowski, R. L. \& Cermák, J. (2002). Strength anisotropy of fiber-reinforced sand. Comput. Geotech. 29, No. 4, 279-299, https://doi.org/10.1016/S0266-352X(01)00032-5.

Miura, K., Miura, S. \& Toki, S. (1986). Deformation behavior of anisotropic dense sand under principal stress axes rotation. Soils Found. 26, No. 1, 36-52, https://doi.org/10.3208/ sandf1972.26.36.

Muir Wood, D., Diambra, A. \& Ibraim, E. (2016). Fibres and soils: a route towards modelling of root-soil systems. Soils Found. 56, No. 5, 765-778.

Sayao, A. \& Vaid, Y. P. (1991). A critical assessment of stress non-uniformities in hollow cylinder test specimens. Soils Found. 31, No. 1, 61-72, https://doi.org/10.3208/sandf1972.31.60.

Soriano, I., Ibraim, E., Andò, E., Diambra, A., Laurencin, T., Moro, P. \& Viggiani, G. (2017). 3D fibre architecture of fibre-reinforced sand. Granular Matter 19, No. 4, 75, https://doi.org/10.1007/s10035-017-0760-3.

Symes, M. J., Gens, A. \& Hight, D. W. (1988). Drained principal stress rotation in saturated sand. Géotechnique 38, No. 1, 59-81, https://doi.org/10.1680/geot.1988.38.1.59.

Tatsuoka, F., Sonoda, S., Hara, K., Fukushima, S. \& Pradhan, T. B. S. (1986). Failure and deformation of sand in torsional shear. Soils Found. 26, No. 4, 79-97.

Vaid, Y., Sayao, A., Hou, E. \& Negussey, D. (1990). Generalised stress-path dependent behaviour with a new hollow cylinder torsional apparatus. Can. Geotech. J. 27, No. 5, 601-616, https://doi.org/10.1139/t90-075.

Yoon, B. S. (2005). Commissioning of a new hollow cylinder apparatus. MSc thesis, University of Bristol, Bristol, UK.

Zornberg, J. G. (2002). Discrete framework for limit equilibrium analysis of fibre-reinforced soil. Géotechnique 52, No. 8, 593-604, https://doi.org/10.1680/geot.2002.52.8.593. 